NBER WORKING PAPER SERIES

\title{
MIDDLEMEN VERSUS MARKET MAKERS: A THEORY OF COMPETITIVE EXCHANGE
}

\author{
John Rust \\ George Hall \\ Working Paper 8883 \\ http://www.nber.org/papers/w8883
NATIONAL BUREAU OF ECONOMIC RESEARCH
1050 Massachusetts Avenue
Cambridge, MA 02138
April 2002

\begin{abstract}
We received helpful feedback from Ian Domowitz, Bruno Jullien, Deborah Minehart, Daniel Spulber, the editor John Cochrane, three anonymous referees, participants at the 2001 Summer Meetings of the Econometric Society, and seminar participants at Harvard Business School, the University of Maryland, CEMFI, U.S. Justice Department, the Federal Reserve Bank of Minneapolis, the Board of Governors of the Federal Reserve System, Universidad Torcuato di Tella, Victoria University, and Yale University. We are especially grateful to an anonymous contact at a U.S. steel service center (i.e., a steel "middleman") who gave us access to confidential data on steel prices and inventories that initiated our inquiry into this topic. We are grateful for financial support from National Science Foundation grant 9905145. Any opinions, findings, and conclusions or recommendations expressed in this material are those of the authors and do not necessarily reflect the views of the National Science Foundation. The views expressed herein are those of the authors and not necessarily those of the National Bureau of Economic Research.
\end{abstract}

(C) 2002 by John Rust and George Hall. All rights reserved. Short sections of text, not to exceed two paragraphs, may be quoted without explicit permission provided that full credit, including (C) notice, is given to the source. 
Middlemen versus Market Makers: A Theory of Competitive Exchange

John Rust and George Hall

NBER Working Paper No. 8883

April 2002

JEL No. D4, D5, D6, D8

\begin{abstract}
We present a model in which the microstructure of trade in a commodity or asset is endogenously determined. Producers and consumers of a commodity (or buyers and sellers of an asset) who wish to trade can choose between two competing types of intermediaries: "middlemen" (dealer/brokers) and "market makers" (specialists). Market makers post publicly observable bid and ask prices, whereas the prices quoted by different middlemen are private information that can only be obtained through a costly search process. We consider an initial equilibrium where there are no market makers but there is free entry of middlemen with heterogeneous transactions costs. We characterize conditions under which entry of a single market maker can be profitable even though it is common knowledge that all surviving middlemen will undercut the market maker's publicly posted bid and ask prices in the post-entry equilibrium. The market maker's entry induces the surviving middlemen to reduce their bid-ask spreads, and as a result, all producers and consumers who choose to participate in the market enjoy a strict increase in their expected gains from trade. We show that strict Pareto improvements occur even in cases where the market maker's entry drives all middlemen out of business, monopolizing the intermediation of trade in the market.
\end{abstract}

John Rust

Department of Economics

University of Maryland

College Park, MD 20742

and NBER

Tel: $301-405-3489$

Fax: 301-405-3542

Email: jrust@gemini.econ.umd.edu

Web: http://gemini.econ.umd.edu/jrust
George Hall

Department of Economics

Yale University

P.O. Box 208268

New Haven, CT 06520-8268

and NBER

Tel: 203-432-3566

Fax: 203-432-6248

Email: george.hall@yale.edu

Web: http://www.econ.yale.edu/ gjh9 
In the early 1970s, the firm [ Cantor Fitzgerald ] vaulted to nearly monopolistic pre-eminence in the bond market by doing something no one else had done before: Cantor began posting government bond prices on computer screens for clients, mainly Wall Street bond dealers, bringing transparency to a market where opacity and rumor had been the norm.

Why would I want to post my prices on the web? If I did that, my competitors could see what I am charging and would undercut my prices by a few pennies, and I would lose most of my business. $^{2}$

\section{Introduction}

We observe significant differences in the microstructure of trade in various commodities and assets. A significant share of trade in commodities such as wheat and pork bellies and in financial assets such as common stocks and Treasury securities is intermediated by market makers (also known as specialists), at publicly posted bid and ask prices. Market makers typically either own or are members of an exchange such as the New York Stock Exchange or the Chicago Board of Trade. However for other commodities such as steel, virtually all trade is conducted by middlemen (also known as dealerbrokers in financial markets or "steel service centers" in the steel market), at individually negotiated prices. In the steel market there are no market makers or exchanges where valid current bid and ask prices are publicly posted. Instead, transaction prices are private information, forcing traders in the steel market to engage in search and bargaining to find a good price.

It is commonly believed that market makers and exchanges are appropriate for trading highly standardized commodities and assets for which the volume is sufficiently large to produce "thick" and "active" markets. However, most types of steel coil and plate are at least as standardized as wheat or pork bellies, and the volume of trade in these particular steel products is at least as large. A number of potential market makers such as MetalSite, e-STEEL, and Enron have recently attempted to enter the steel market, but so far without success. Enron went bankrupt in December 2001, MetalSite's website was closed in June 2001 (although it was reopened in November 2001), and e-STEEL changed its name to NewView Technologies in November 2001, reflecting a new focus away from steel. Thus, at present no market makers handle a significant share of trade in steel. So the first puzzle is to explain why market makers such as Cantor Fitzgerald have been successful in entering and transforming the trade in bonds, but not in steel.

\footnotetext{
${ }^{1}$ Zuckerman, Gregory, Ann Davis, and Suzanne McGee, "Before and After: Why Cantor Fitzgerald Can Never Re-Create What It Once Was," Wall Street Journal, October 26, 2001, page A1.

${ }^{2} \mathrm{~A}$ private communication to the authors by a middleman in the steel service center industry.
} 
The second quotation above suggests that even though new information technologies such as the Internet make it nearly costless to post and update bid and ask prices publicly, it might still be unprofitable for potential market makers to enter markets such as steel. If buyers of steel are accustomed to searching, then middlemen can easily respond to the entry of a market maker by slightly undercutting the market maker's prices, stealing most of his business. So the second puzzle is to explain how a market maker such as Cantor Fitzgerald can successfully enter a market such as the bond market if the existing middlemen can respond by undercutting the market maker's publicly posted bid and ask prices.

As a step toward answering these puzzles and understanding the differences in the microstructure of trade that we observe across various markets, we present a simple model in which the share of trade intermediated by middlemen and market makers is endogenously determined. Our model also provides insights into the likely effects of the huge reduction in search and transactions costs resulting from the information revolution and the advent of the World Wide Web. These technologies have facilitated the rapid emergence of market makers operating web-based "B2B exchanges" that intermediate business-tobusiness trade, threatening the existence of traditional middlemen in these markets.

Our model is an extension of a model of intermediation and search due to Spulber (1996a). Spulber's model has three types of agents: buyers (consumers), sellers (producers), and price-setting middlemen. Since middlemen are often called dealers, we refer to Spulber's model as an analysis of the dealer market. Our main extension is to consider the effect of introducing a fourth type of agent, market makers. In Spulber's model, middlemen are assumed to be the exclusive avenue of exchange: every producer wishing to sell a commodity (or asset) and every consumer wishing to purchase it is required to transact via middlemen rather than trade directly with each other. Transactions in the dealer market occur over a range of individually negotiated prices - the outcome of a costly sequential search process.

We study the effect of introducing a monopolist market maker on the search equilibrium in the dealer market. The market maker can be conceptualized as operating an exchange on which publicly observable bid and ask prices are posted. Producers and consumers now have the option of trading on the exchange at the publicly posted bid and ask prices, or searching for a better price in the dealer market. Since the prices quoted by middlemen are not publicly posted, producers and consumers must obtain them by direct

\footnotetext{
${ }^{3}$ The rate of growth of B2B markets is nothing short of phenomenal: Forrester Research predicts that sales via computerized market makers will expand fivefold in the next two years and will account for at least 25 percent of all sales in 2002, and a total volume of $\$ 1.4$ trillion in transactions by 2004 . These estimates may be conservative: alternative forecasts quoted in a recent symposium on B2B e-commerce published in the Journal of Economic Literature are substantially higher. See, for example, Lucking-Reiley and Spulber (2001) and Bakos (2001) for even more optimistic forecasts of rapid growth in retail e-commerce.
} 
contact (e.g., a telephone call), and the delays associated with searching constitute an implicit search cost.

Entry by a monopolist market maker is profitable even if the market maker has higher per unit transactions cost than most middlemen, provided that it is lower than that of the least efficient middleman operating in the dealer market before the entry of the market maker. If so, the entry of the market maker drives the least efficient middle men out of business and segments the market: the highest-valuation consumers and the lowest-cost producers (i.e., those with the largest implicit search costs) trade with the market maker, and the residual set of intermediate-valuation consumers and intermediate-cost producers search for better prices in the dealer market. All of the surviving middlemen undercut the bid-ask spread charged by the monopolist market maker. Thus the entry of the monopolist market maker creates additional competition that results in significant reductions in the bid-ask spreads in the dealer market, uniformly higher consumer and producer surpluses, and higher trading volumes.

Middlemen and market makers represent competing institutions for the intermediation of trade. A market maker offers a superior exchange technology for the highest-valuation buyers and the lowest-cost sellers, and its entry raises welfare and reduces bid-ask spreads compared with the free-entry search equilibrium when all intermediation is done by middlemen. On the other hand, free entry of middlemen provides a "competitive fringe" that limits the market power of a monopolist market maker. Without the competitive threat of middlemen, a monopolist market maker would quote a wider bid-ask spread, and consumer and producer surplus would be significantly lower. However in some situations the market maker can enter the market, drive all middlemen out of business, and set unconstrained monopoly bid and ask prices in the post-entry equilibrium. Even this monopoly outcome results in a strict Pareto improvement relative to the free-entry equilibrium that existed in the dealer market before the entry of the market maker.

The relative share of trade intermediated by middlemen rather than the market maker depends on three parameters: the intertemporal discount rate $\delta$ and the per unit transactions costs of the market maker $k_{n}$ and most efficient middleman $\underline{k}$. For a broad range of parameter values, the market maker coexists with the dealer market. However if the market maker's per unit transactions cost $k_{m}$ exceeds that of the least efficient middleman $\bar{k}$ operating in the dealer market before the entry of a market maker, then entry by the market maker is not profitable and only middlemen will exist in equilibrium. Conversely, if the per unit transactions cost of the most efficient middleman $\underline{k}$ is sufficiently high relative to the transactions cost of the market maker $k_{m}$, then the entry of the market maker drives all middlemen out of business. The dealer market can survive the entry of a market maker even if the transactions cost $\underline{k}$ of the most efficient middleman exceeds the transactions cost $k_{m}$ of the market maker - provided it is not too much greater. 
Our analysis is similar in some respects to those of Gehrig (1993) and Neeman and Vulkan (2001), although our conclusions are quite different. ${ }^{4}$ Gehrig studies a model in which producers and consumers of a commodity have the option of trading at publicly posted bid and ask prices on an exchange run by a market maker (which Gehrig calls an "intermediary"), or entering a "search market" in which consumers and producers are randomly matched and engage in bargaining in an attempt to negotiate a mutually acceptable price. Gehrig's model differs from ours primarily in the formulation of the search market; he models the bargaining process in the search market as a static (one-shot) random matching game in which consumers and producers negotiate directly with each other rather than transacting through middlemen. In Gehrig's model the market maker always coexists with the search market and charges the same bid-ask spread and trades the same volume regardless of the level of search costs in the search market. Neeman and Vulkan (2001) obtain a very different result, namely, that the market maker can never coexist with the search market in equilibrium. In their model agents have a choice between trading at posted prices with a market maker in a centralized market and engaging in direct negotiations with a randomly chosen producer or consumer in the search market. They prove a result similar to ours, namely, that the highest-valuation consumers and lowest-cost producers prefer to trade with the market maker rather than engage in direct negotiation. However, in their model the entry of a market maker causes a complete unraveling of direct negotiations, and in equilibrium all trade is conducted in the centralized market by the market maker.

In section 2 we review a dynamic equilibrium model, introduced by Spulber (1996a), of trade with search among competing middlemen. In section 3 we consider whether the dealer market equilibrium characterized in section 2 can be upset by the entry of a monopolist market maker who runs a centralized exchange with publicly posted prices. In section 4 we consider the case where there is free entry of market makers, resulting in Bertrand-style competition that forces the bid-ask spread down to the transactions cost of the most efficient market maker. Although our interest in alternative intermediation technologies arose from our observations of the microstructure of trade in the steel market, we believe our theory provides insights into the microstructure of trade in a wide range of markets. In section 5 we discuss three other markets besides steel: the market for goods in Radford's (1945) P.O.W. camp, the U.S. equity market, and the U.S. Treasury market. In section 6 we offer some concluding remarks and suggestions for further research.

\footnotetext{
${ }^{4}$ We discuss related papers by Baye and Morgan (2001), Caillaud and Jullien (2001), Pirrong (2000), and Hendershott and Zhang (2001) later in the paper. A number of other studies on the role of intermediaries deserve mention although we do not explicitly discuss them. An incomplete list includes Garman (1976), Rubinstein and Wolinsky (1987), Yanelle (1989), Yavas (1992), and O'Hara (1995).
} 


\section{Search Equilibrium with Middlemen but No Market Maker}

Our point of departure is a simple exchange economy in which the only intermediaries are middlemen. We present a modified version of Spulber's (1996a) equilibrium search model with three types of agents: producers, consumers, and middlemen. In this model producers and consumers cannot trade directly with each other. Instead all trade must be intermediated by middlemen. To keep our presentation self-contained, we review Spulber's model in this section before presenting our extension of his model in which we analyze the effect of introducing a fourth type of agent - a market maker. Since middlemen of the type studied in this section are called dealers in a variety of financial and commodity markets, we refer to Spulber's work as an analysis of a competitive dealer market.

The dealer market consists of a continuum of heterogeneous producers, consumers, and middlemen. A producer of type $v$ can produce at most one unit of the good at a cost of $v$. A consumer of type $v$ can consume at most one unit of the good and is willing to pay at most $v$ to consume it. Producers and consumers remain in the market for a random (geometrically distributed) length of time before permanently exiting. Let $\lambda \in(0,1)$ be the probability of a producer or a consumer exiting the market in period $t$. A consumer or producer may randomly exit before having a chance to consume or sell a unit of the good, respectively. However, if they succeed in trading prior to exiting, the unitary supply-demand assumption implies that these individuals will not make any subsequent transactions after their initial trade.

Suppose that whenever a producer or a consumer exits the market, he or she is replaced by a new producer or consumer who is randomly drawn from $U[0,1]$, the uniform distribution on the $[0,1]$ interval. Suppose that at time $t=0$ the initial distribution of types $v$ of producers and consumers is $U[0,1]$. Then in all subsequent periods $t=1,2,3 \ldots$ the distribution of types will also be $U[0,1]$. Thus $U[0,1]$ is the unique, invariant distribution of this entry and exit process, and in each subsequent period $t=1,2,3, \ldots$ a fraction $\lambda$ of the population of producers and consumers exits the market and is replaced by an inflow of an equal fraction of new producers and consumers.

In a dealer market there is no central exchange or marketplace where the commodity is traded. In particular, there is no advertising or central, publicly accessible site where middlemen can post bid and ask prices. Instead, the only way for producers and consumers to obtain price quotes is by directly contacting individual middlemen. Middle men are infinitely lived and set a pair of stationary bid and ask prices to maximize their expected discounted profits. There are a continuum of middlemen indexed by $k$, the marginal costs of executing each trade between a producer and a consumer. Transactions costs $k$ are 
distributed uniformly over the interval $[\underline{k}, 1]$. The lower bound $\underline{k}$ is the marginal transactions cost of the most efficient middleman. It may not be possible for all potential middlemen to enter the dealer market and make a profit. We will let $\bar{k}$ denote the transactions cost of the least efficient middleman who participates in the dealer market in equilibrium. Thus profits earned by this marginal middleman $\bar{k}$ are zero, although the more efficient, inframarginal middlemen with $k \in[k, \bar{k})$ can earn positive profits in equilibrium. A middleman of type $k \in[\underline{k}, \bar{k}]$ chooses a pair of stationary bid and ask prices $(b(k), a(k))$ that maximizes his expected discounted profits, where $a(k)$ denotes the ask price at which the middleman is willing to sell to consumers, and $b(k)$ denotes the bid price at which the middleman is willing to purchase from producers.

Producers and consumers engage in sequential search. Each period a searcher obtains a single price quote from one middleman, drawn randomly from $U[\underline{k}, \bar{k}]$. Although there is no explicit cost to obtain a price quote, there is an implicit "delay cost" involved in searching for prices. All producers and consumers discount the future using the factor $\rho(1-\lambda)$. The first term in this composite discount factor, $\rho \in(0,1)$, reflects the rate of time preference, and the second, $(1-\lambda)$, is the "survival probability" that accounts for the possibility of random exit from the market prior to trading (in which case the exiting agent fails to receive any gains from trade). ${ }^{5}$ The stationarity of the bid and ask prices charged by middlemen together with the heterogeneity in their transactions costs implies that the sequence of realized price quotes obtained by consumers and producers are independently and identically distributed (i.i.d.) draws from the stationary distributions of bid and ask prices charged by middlemen. Let $F_{\alpha}(a)$ denote the distribution of ask prices facing consumers and $F_{\beta}(b)$ denote the distribution of bid prices facing producers.

Let $V_{c}(a, v)$ denote the present discounted value of an optimal search strategy for a consumer of type $v$ who has received a quoted ask price of $a$ from a randomly chosen middleman. The consumer has three choices: a) do nothing (i.e., do not buy at the ask price $a$ and do not search), b) accept the middleman's ask price of $a$, or c) reject the middleman's ask price of $a$ and continue searching for a better price. These three options are reflected in the following Bellman equation for the consumer's problem:

$$
V_{c}(a, v)=\max \left[0, v-a, \rho(1-\lambda) \int_{\underline{a}}^{\bar{a}} V_{c}\left(a^{\prime}, v\right) F_{\alpha}\left(d a^{\prime}\right)\right],
$$

where $[\underline{a}, \bar{a}]$ is the support of the distribution of ask prices charged by middlemen. The value of 0 in the Bellman equation corresponds to the option of not searching, not trading, and not consuming. All

\footnotetext{
${ }^{5}$ It is possible to extend the model by including explicit per period search costs $\gamma$. However, it is not difficult to show that a stationary equilibrium in the dealer market cannot exist if $\gamma>0$. Therefore we restrict $\gamma=0$ in the analysis that follows, accounting only for the implicit search costs resulting from exiting the market before having an opportunity to execute a transaction (the $\lambda$ parameter), and the discounting of delayed gains from trade (the $\rho$ parameter).
} 
consumers with sufficiently low valuations will choose this option. Clearly, any consumer with valuation $v<\underline{a}$ will never search or trade in the dealer market.

Now consider the remaining high-valuation consumers. As is well known, the optimal search strategy for a consumer of type $v$ takes the form of a reservation price rule: accept any ask price less than the reservation price $r_{c}(v)$, where $r_{c}(v)$ is the function implicitly defined by the unique solution to

$$
v=r_{c}(v)+\frac{1}{\delta} \int_{\underline{a}}^{r_{c}(v)} F_{\alpha}(a) d a
$$

where

$$
\delta=\delta(\rho, \lambda)=\frac{1}{\rho(1-\lambda)}-1
$$

is the composite exit-adjusted per period discount rate. It is not difficult to see from equation (2) that $k(v)$ is a strictly increasing function of $v$ on the interval $\left(\underline{v}_{c}, 1\right)$, where $\underline{v}_{c}$ is the marginal consumer for whom the gain from entering the dealer market is zero. We have $\underline{v}_{c}=r_{c}\left(\underline{v}_{c}\right) \equiv \underline{r}_{c}=\underline{a}$.

Let $V_{p}(b, v)$ denote the present discounted value of an optimal search strategy of a producer of type $v$ facing a bid price of $b$. The Bellman equation for the producer is given by

$$
V_{p}(b, v)=\max \left[0, b-v, \rho(1-\lambda) \int_{\underline{b}}^{\bar{b}} V_{p}\left(b^{\prime}, v\right) F_{\beta}\left(d b^{\prime}\right)\right],
$$

where $[\underline{b}, \bar{b}]$ is the support of the distribution of bid prices offered by middlemen. The optimal strategy for a producer of type $v$ also takes the form of a reservation price strategy, but in this case it is optimal to accept any bid price $b$ that exceeds the reservation price $r_{p}(v)$, given by the unique solution to

$$
v=r_{p}(v)-\frac{1}{\delta} \int_{r_{p}(v)}^{\bar{b}}\left[1-F_{\beta}(b)\right] d b .
$$

In the producer case $r_{p}(v)$ is monotonically increasing over the interval $\left(0, \bar{v}_{p}\right)$ where $\bar{v}_{p}=r_{p}\left(\bar{v}_{p}\right) \equiv \bar{r}_{p}=\bar{b}$ is the marginal producer for whom the expected gain from searching is zero.

Figure 1 graphs the reservation price functions $r_{c}(v)$ and $r_{p}(v)$ for an example where $\delta=.2$ with a specific (equilibrium) pair of bid and ask distributions $F_{\alpha}$ and $F_{\beta}$ that will be derived shortly. Valuations for buyers are plotted from high to low, whereas sellers' costs are plotted from low to high, resulting in notional "supply" and "demand" curves. However, actual transactions in this market are determined by producers' and consumers' optimal search behavior. Consumers purchase the good from middlemen at prices in the interval $[\underline{a}, \bar{a}]=[.61, .71]$, and producers sell the good to middlemen at prices in the interval $[\underline{b}, \bar{b}]=[.28, .39]$. Note that the reservation price function for producers, $r_{p}(v)$, lies uniformly above the 
sellers' supply curve, provided that the producer participates in the dealer market. It is easy to see from equation (5) that when the seller's cost $v$ exceeds the upper bound $\bar{b}$ of the distribution $\bar{\beta}$ of bid prices offered by middlemen, there is no point in searching. Thus all producers with costs $v>\bar{b}=\bar{v}_{p}=.39$ remain out of the market. Symmetrically, the reservation price function for buyers lies uniformly below their valuations, intersecting it at the lower support point $\underline{a}=\underline{v}_{c}=.61$ of the distribution of ask prices $F_{\alpha}$. Therefore the set of active consumers are those for whom $v \in\left(\underline{v}_{c}, 1\right]=(\underline{a}, 1]=(.61,1]$.

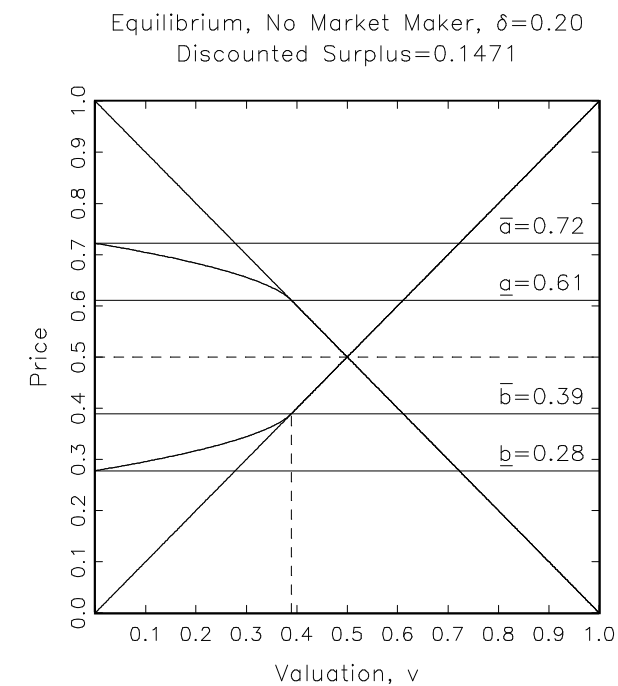

\section{Figure 1: Reservation Prices for Buyers (Consumers) and Sellers (Producers)}

Along the abscissa, buyers' valuations are plotted from high to low, whereas sellers' valuations (costs) are plotted from low to high.

The difference between a consumer's valuation $v$ and his or her reservation value $r_{c}(v)$ is the net value of search, i.e. the expected discounted surplus or "gains from trade." For reference, we plot a horizontal dashed line of height equal to .5 in figure 1 . The area in the triangular regions between the 45 -degree line and this horizontal line (and to the left of the intersection of the "supply" and "demand" curves) represents the surplus that consumers and producers would achieve in a frictionless Walrasian equilibrium, where the equilibrium price for the good equals $p^{*}=.5$. In that case the surplus for a consumer with valuation $v$ is given by $\max [0, v-.5]$, and the surplus for a producer with cost $v$ is given by $\max [0, .5-v]$. The area of the triangular regions, i.e. the surplus achieved by producers and consumers in Walrasian equilibrium, is $1 / 8$ and $1 / 8$, respectively, resulting in a total surplus of $1 / 4$. The area between the horizontal dashed line and the reservation price curves represents the inefficiency of the search equilibrium outcome, i.e. the lost gains from trade to producers and consumers.

Intermediaries maximize expected discounted profits subject to the constraint that supply and demand 
for the commodity are equal in every period. This constraint is necessitated by the assumption that middlemen do not carry inventories across successive periods. Suppose a middleman sets an ask price of $a$. Let $D_{i}(a)$ denote the mass of consumers who were among the initial population at $t=0$ who purchase the good in period $i$

$$
D_{i}(a)=\frac{1-\underline{v}_{c}}{N} \int_{a}^{\bar{r}_{c}}(1-\lambda)^{i}\left[1-F_{\alpha}(r)\right]^{i} h(r) d r
$$

where $N$ is the number (total mass) of middlemen, $\bar{r}_{c} \equiv r_{c}(1)$ is the reservation price of the highestvaluation buyer, and $h(r)$ is the (conditional) distribution of reservation prices among the fraction $1-\underline{x}$ of the initial population of consumers who chose to participate in the dealer market. Thus, $h(r)\left[1-\underline{\nu}_{c}\right] / N$ is the per-firm density of consumers. So $D_{i}(a)$ equals the integral of the product of the probability $(1-\lambda)^{j}$ of not exiting the market in periods $t=0,1, \ldots, i-1$ times the probability $\left[1-F_{\alpha}(r)\right]^{i}$ of not trading in periods $0, \ldots, i-1$, times the per-firm density of consumers $h(r)\left[1-\underline{v}_{c}\right] / N$, integrated over the region of reservation values $\left[a, \bar{r}_{c}\right]$ corresponding to buyers who are willing to purchase at price $a$. By a change of variables, the density $h(r)$ can be derived from the distribution $r_{c}(v)$ and the fact that the valuations of those consumers who participate in the dealer market are uniformly distributed on $\left.\varliminf_{c}, 1\right]$ :

$$
h(r)=\left[\frac{1}{1-\underline{v}_{c}}\right]\left[\frac{d r_{c}}{d v}\left(r_{c}^{-1}(r)\right)\right]^{-1}=\frac{1+F_{\alpha}(r) / \delta}{1-\underline{v}_{c}} .
$$

Let $D_{i}$ be the share of the initial population that purchases from any middleman at time $i$ :

$$
D_{i}=\int_{\underline{a}}^{\bar{a}} D_{i}(a) F_{\alpha}(d a)=\int_{\underline{v_{c}}}^{1}(1-\lambda)^{i}\left[1-F_{\alpha}(v)\right]^{i} F_{\alpha}(v) d v .
$$

It is not hard to verify that, when $\lambda>0$, the share of consumers who ultimately purchase the good is less than the share of consumers who choose to search for it in the dealer market:

$$
\sum_{i=0}^{\infty} D_{i}=\int_{\underline{v}_{c}}^{1} \frac{F_{\alpha}(v)}{1-(1-\lambda)\left[1-F_{\alpha}(v)\right]} d v<1-\underline{v}_{c} .
$$

This occurs since some of the consumers who attempted to search for the good ended up exiting the dealer market before they were able to find a sufficiently attractive price. This is part of the deadweight loss involved in the operation of the dealer market. Another component of the deadweight loss due to sequential search and the implied delay in trading and consuming is the discounting of the gains from trade for those transactions that are ultimately realized.

Total expected discounted demand is the expected discounted value of the stream of demands in all future periods by the initial population at time $t=0$ as well as the stream of demands from each succeeding generation of new producers and consumers entering the dealer market. The subsequent entrants are drawn 
from the same $U[0,1]$ distribution of types as the initial population of producers and consumers at $t=0$, but their mass is scaled by the factor $\lambda$, the fraction of the population entering and exiting each period. Assuming that all middlemen discount future flows using the discount factor $\rho$, we have

$$
\begin{aligned}
D(a) & =\sum_{i=0}^{\infty} \rho^{i} D_{i}(a)+\lambda \sum_{j=1}^{\infty} \rho^{j} \sum_{i=0}^{\infty} \rho^{i} D_{i}(a) \\
& =\frac{\left[1-\underline{v}_{c}\right]}{N} \int_{a}^{\bar{r}_{c}}\left[\sum_{i=0}^{\infty} \rho^{i}(1-\lambda)^{i}\left[1-F_{\alpha}(r)\right]^{i}+\lambda \sum_{j=1}^{\infty} \rho^{j} \sum_{i=0}^{\infty} \rho^{i}(1-\lambda)^{i}\left[1-F_{\alpha}(r)\right]^{i}\right] h(r) d r \\
& =\frac{1}{N} \int_{a}^{\bar{r}_{c}}\left[\frac{1+\rho \lambda /(1-\rho)}{1-\rho(1-\lambda)\left[1-F_{\alpha}(r)\right]}\right]\left[\frac{\delta(\rho, \lambda)+F_{\alpha}(r)}{\delta(\rho, \lambda)}\right] d r \\
& =\frac{1}{N} \int_{a}^{\bar{r}_{c}}\left[\frac{1+\rho \lambda /(1-\rho)}{1-\rho(1-\lambda)+\rho(1-\lambda) F_{\alpha}(r)}\right]\left[\frac{1-\rho(1-\lambda)+\rho(1-\lambda) F_{\alpha}(r)}{1-\rho(1-\lambda)}\right] d r \\
& =\frac{\bar{r}_{c}-a}{N}\left[\frac{1+\rho \lambda /(1-\rho)}{1-\rho(1-\lambda)}\right] .
\end{aligned}
$$

By similar reasoning the middleman's expected discounted supply function is

$$
S(b)=\frac{b-\underline{r}_{p}}{N}\left[\frac{1+\rho \lambda /(1-\rho)}{1-\rho(1-\lambda)}\right]
$$

where $\underline{r}_{p} \equiv r_{p}(0)$ is the reservation value of the lowest-cost producer. Given the discounted supply and demand functions, the middleman's present discounted value of future trading profits is given by

$$
\Pi(a, b, k)=a D(a)-(b+k) S(b)=\left[\frac{1+\rho \lambda /(1-\rho)}{1-\rho(1-\lambda)}\right]\left[\frac{a\left(\bar{r}_{c}-a\right)-(b+k)\left(b-\underline{r}_{p}\right)}{N}\right] .
$$

The middleman's problem is to:

$$
\max _{a, b} \Pi(a, b, k) \quad \text { subject to: } D(a) \leq S(b) .
$$

The optimal bid and ask prices are

$$
\begin{aligned}
& a(k)=\left(3 \bar{r}_{c}+\underline{r}_{p}+k\right) / 4 \\
& b(k)=\left(\bar{r}_{c}+3 \underline{r}_{p}-k\right) / 4 .
\end{aligned}
$$

These bid and ask prices also equate supply and demand in every period: $D_{l}(a(k))=S_{i}(b(k)), i=0,1,2 \ldots$

The linearity of $a(k)$ and $b(k)$ in $k$ implies that the distributions of the bid and ask prices $F_{\alpha}$ and $F_{\beta}$ are uniform. To find the support of these distributions, we need to compute $\bar{k}$, the transactions cost of the marginal middleman entering the dealer market in equilibrium. Plugging the solutions in equation (14) back into the profit function (12), we obtain

$$
\Pi(a(k), b(k), k)=\left[\frac{1+\rho \lambda /(1-\rho)}{1-\rho(1-\lambda)}\right]\left[\frac{\left(\bar{r}_{c}-\underline{r}_{p}-k\right)^{2}}{8 N}\right] .
$$


Solving for $\Pi(a(k), b(k), k)=0$, we see that the marginal middleman has a transactions cost of $\bar{k}=\bar{r}_{c}-\underline{r}_{p}$, and the number of middlemen operating in equilibrium is $N=\bar{k}-\underline{k}=\bar{r}_{c}-\underline{r}_{p}-\underline{k}$. Letting $k$ equal $\underline{k}$ and $\bar{k}$, we obtain supports of the equilibrium distributions of bid and ask prices. The upper and lower support points of the distribution of bid and ask prices are functions of the highest and lowest reservation values of buyers and sellers. This characterization will play a key role in section 3 when we analyze how the dealer market is affected by the potential entry of a market maker.

Lemma 1: If $\underline{k}<1$, there is a unique stationary equilibrium in the dealer market. Bid prices are uniformly distributed on the interval $[\underline{b}, \bar{b}]$, and ask prices are uniformly distributed on the interval $[a, \bar{a}]$, where

$$
\begin{array}{ll}
\bar{a}=\bar{r}_{c}, & \underline{a}=\underline{r}_{c}=.25\left(\underline{r}_{p}+\underline{k}\right)+.75 \bar{r}_{c} \\
\underline{b}=\underline{r}_{p}, & \bar{b}=\bar{r}_{p}=.75 \underline{r}_{p}+.25\left(\bar{r}_{c}-\underline{k}\right) .
\end{array}
$$

To complete the characterization of the dealer market equilibrium, we need to derive expressions for the reservation values of the highest-valuation consumer $\bar{r}_{c}$ and the lowest-cost seller $\underline{r}_{p}$ in terms of the underlying preference and technology parameters $(\rho, \lambda, \underline{k})$. Substituting the uniform distribution $F_{\alpha}$ of ask prices and the expression for its lower support point $\underline{a}$ into equation (2) for the consumer with the highest reservation value $\bar{r}_{c}=r_{c}(1)$, we obtain

$$
\begin{aligned}
1 & =\bar{r}_{c}+\frac{1}{\delta} \int_{\underline{a}}^{\bar{r}_{c}} F_{\alpha}(a) d a \\
& =\frac{(1+8 \delta) \bar{r}_{c}-\underline{r}_{p}-\underline{k}}{8 \delta} .
\end{aligned}
$$

Similarly, substituting $F_{\beta}$ and the formula for its upper support point $\bar{b}$ into the reservation price equation (5) for the producer with the lowest reservation value $\underline{r}_{p}=r_{p}(0)$, we obtain

$$
\begin{aligned}
0 & =\underline{r}_{p}-\frac{1}{\delta} \int_{\underline{r}_{p}}^{\bar{b}}\left[1-F_{\beta}(b)\right] d b \\
& =\frac{(1+8 \delta) \underline{r}_{p}-\bar{r}_{c}+\underline{k}}{8 \delta} .
\end{aligned}
$$

Solving these equations for $\bar{r}_{c}$ and $\underline{r}_{p}$, we obtain $1=\bar{r}_{c}+\underline{r}_{p}$, which implies that

$$
\bar{r}_{c}=\frac{1+\underline{k}+8 \delta}{2+8 \delta}, \quad \text { and } \quad \underline{r}_{p}=\frac{1-\underline{k}}{2+8 \delta}
$$

The fraction of consumers and producers who participate in the dealer market is given by

$$
q^{*}=1-\underline{v}_{c}=\bar{r}_{p}=\frac{(1-\underline{k})(1+2 \delta)}{2+8 \delta} .
$$


The distribution of ask prices $F_{\alpha}$ is uniform on the interval

$$
\left[\frac{1+6 \delta+\underline{k}(1+2 \delta)}{2+8 \delta}, \frac{1+\underline{k}+8 \delta}{2+8 \delta}\right] .
$$

The distribution of bid prices $F_{\beta}$ is uniform on the interval

$$
\left[\frac{1-\underline{k}}{2+8 \delta}, \frac{(1-\underline{k})(1+2 \delta)}{2+8 \delta}\right] \text {. }
$$

We can see from these equations that as $\delta \downarrow 0$ and $\underline{k} \downarrow 0$, the distributions of bid and ask prices converge to a degenerate distribution with all mass on the single price $p=.5$, the Walrasian equilibrium value. We can also see from equation (20) that the equilibrium quantity traded also converges to $q=.5$, the Walrasian equilibrium quantity. Thus the dealer market equilibrium contains the Walrasian equilibrium as a limiting special case as search and transactions costs tend to zero.

The mass of middlemen who are active in equilibrium is given by

$$
N=\bar{k}-\underline{k}=\frac{4 \delta(1-\underline{k})}{1+4 \delta} .
$$

Note that the dealer market collapses to a no-trade equilibrium as $\underline{k} \rightarrow 1$. We also have $N \downarrow 0$ in the limit as $\delta \downarrow 0$. In this case the dealer market is not collapsing, but rather converging to a degenerate distribution where the most efficient middleman handles all trade, setting an ask price of $\bar{a}=\underline{a}=(1+\underline{k}) / 2$ and a bid price of $\bar{b}=\underline{b}=(1-\underline{k}) / 2$. This is a zero-profit equilibrium, since the bid-ask spread of $\underline{k}$ just offsets the transactions cost of the most efficient middleman. As $\underline{k} \downarrow 0$, the competitive positive transactions cost equilibrium converges to the frictionless Walrasian equilibrium outcome.

We conclude by providing formulas for profits and surplus in this economy. These formulas will be important in the next section, since they enable us to determine the relative efficiency of the dealer market equilibrium compared with an equilibrium with possible entry by a market maker. Total consumer and producer surplus, denoted by $S_{c}$ and $S_{p}$ respectively, are given by

$$
S_{c}=[1+\lambda \rho /(1-\rho)] \int_{0}^{1}\left[v-r_{c}(v)\right] d v, \quad S_{p}=[1+\lambda \rho /(1-\rho)] \int_{0}^{1}\left[r_{p}(v)-v\right] d v,
$$

where we set $r_{c}(v)=v$ for the consumers who do not trade and $r_{p}(v)=v$ for producers who do not trade, so these individuals do not contribute to total surplus. The factor $[1+\lambda \rho /(1-\rho)]$ adjusts for the discounted surplus of all current and future consumers and producers who enter the market.

The total discounted profits of all middlemen participating in the dealer market is given by

$$
\Pi_{d} \equiv \int_{\underline{k}}^{\bar{k}} \Pi(a(k), b(k), k) d k=\left[1+\frac{\rho \lambda}{(1-\rho)}\right]\left[\frac{(1+\delta) N^{2}}{24 \delta}\right] .
$$


We see from this formula that total profits of middlemen tend to 0 as $\delta \downarrow 0$ (due to convergence to a zero-profit competitive equilibrium) or as $\underline{k} \uparrow 1$ (due to convergence to a no-trade equilibrium).

The total gain from trade from the operation of the dealer market, $W^{d}$, is the sum of producer surplus, consumer surplus, and the total discounted profits of middlemen

$$
W^{d}=S_{c}+S_{p}+\Pi_{d}
$$

In the limiting Walrasian equilibrium, we have $S_{c}=S_{p}=.125$ and $\Pi_{d}=0$, so the total surplus equals $W^{d}=.25$, the area under the notional supply and demand curves to the left of the intersection at $q=.5$. When $\delta=.2, \lambda=0$, and $\underline{k}=0$, we compute $S_{c}=S_{p}=.0489$ and $\Pi_{d}=.0494$, so that the total surplus equals $W^{d}=.1471$, which is only 59 percent of the maximum possible surplus of .25 that would be achieved in a frictionless Walrasian equilibrium.

\section{Search Equilibrium with a Monopoly Market Maker}

In this section we extend Spulber's (1996a) model of search equilibrium with producers, consumers, and middlemen by introducing a fourth type of agent: a monopolist market maker. Initially we assume there is at most one potential entrant who could assume the role of a monopolist market maker, quoting publicly observable bid and ask prices $\left(a_{m}, b_{m}\right)$. If this market maker enters, producers and consumers can choose between trading with the market maker at the publicly posted bid and ask prices $\left(a_{m}, b_{m}\right)$, and searching for a better bid or ask price in the dealer market.

We begin our analysis by characterizing how the presence of a market maker affects the solution to consumers' and producers' optimal search problems. We then derive conditions under which entry by a market maker is profitable and compute the market maker's optimal pricing strategy. In doing so, we compute the dealer's equilibrium response to the market maker's entry and pricing rules. We then compare equilibrium outcomes for economies with and with out a market maker. Finally we summarize the limiting properties the model.

\subsection{The consumers' and producers' decision rules}

Consider a consumer who has not yet chosen to search. The consumer has three options: a) do nothing, b) purchase a unit of the commodity in the exchange at price $a_{m}$, or c) search for a better price in the dealer market. The consumer's value function is given by

$$
V_{c}\left(a_{m}, v\right)=\max \left[0, v-a_{m}, \rho(1-\lambda) \int_{\underline{a}}^{\bar{a}} V_{c}\left(a^{\prime}, a_{m}, v\right) F_{\alpha}\left(d a^{\prime}\right)\right] .
$$


where $V_{c}\left(a, a_{m}, v\right)$ denotes the value function for a consumer who has chosen to search and has received an ask price of $a$ from a middle man, modeled as a random draw from $F_{\alpha}$. Once the consumer has an offer in hand, he has the fourth options of accepting the offer from the middleman. The Bellman equation for $V_{c}\left(a, a_{m}, v\right)$ is given by

$$
V_{c}\left(a, a_{m}, v\right)=\max \left[0, v-a, v-a_{m}, \rho(1-\lambda) \int_{\underline{a}}^{\bar{a}} V_{c}\left(a^{\prime}, a_{m}, v\right) F_{\alpha}\left(d a^{\prime}\right)\right] .
$$

Theorem 1: Suppose an equilibrium exists where the market maker coexists with middlemen in the dealer market. Let $\underline{a}$ be the lowest ask price in the dealer market after the entry of the market maker. Let $v_{c}\left(\underline{a}, a_{m}\right)$ be the value of the marginal consumer (with reservation value $a_{m}$ ), who is indifferent between trading with the market maker and trading in the dealer market:

$$
v_{c}\left(\underline{a}, a_{m}\right)=a_{m}+\frac{1}{\delta} \int_{\underline{a}}^{a_{m}} F_{\alpha}(a) d a .
$$

If $v_{c}\left(\underline{a}, a_{m}\right)<1$, then there are three different optimal search-purchase strategies depending on the consumer's type. If $v \in[0, \underline{a})$, then it is not optimal for the consumer to trade with the market maker or to search for a middleman in the dealer market. If $v \in\left[\underline{a}, v_{c}\left(\underline{a}, a_{m}\right)\right)$, then it is optimal for the consumer to trade in the dealer market. If $v \in\left(v_{c}\left(\underline{a}, a_{m}\right), 1\right]$, then it is optimal for the consumer to bypass the dealer market and to immediately purchase the good from the market maker at the ask price $a_{n}$.

We also have a symmetric result for producers, namely:

Theorem 2: Suppose an equilibrium exists where the market maker coexists with middlemen in the dealer market. Let $v_{p}\left(b_{m}, \bar{b}\right)$ be the value of the marginal producer (with reservation value $b_{m}$ ), who is indifferent between trading with the market maker and trading in the dealer market:

$$
v_{p}\left(b_{m}, \bar{b}\right)=b_{m}-\frac{1}{\delta} \int_{b_{m}}^{\bar{b}}\left[1-F_{\beta}(b)\right] d b .
$$

If $v_{p}\left(b_{m}, \bar{b}\right)>0$, then there are three different optimal search-sell strategies depending on the producer's type. If $v \in(\bar{b}, 1]$, then it is not optimal for the producer to trade with the market maker or to search for a middleman in the dealer market. If $v \in\left(v_{p}\left(b_{m}, \bar{b}\right), \bar{b}\right]$, then it is optimal for the producer to trade in the dealer market. If $v \in\left[0, v_{p}\left(b_{m}, \bar{b}\right)\right]$, then it is optimal for the producer to bypass the dealer market and to immediately sell the good to the market maker at the bid price $b_{m}$.

Figure 2 illustrates Theorems 1 and 2 for the case where $\delta=0.2$. The curved line in the left panel is the net value of search for consumers, $v-r_{c}(v)$, and in the right panel it is the value of search for producers, $r_{p}(v)-v$. The straight lines plotted in each panel of figure 2 are net values of trading with the market 
maker at the publicly posted bid and ask prices $\left(a_{m}, b_{m}\right)$; that is, they are graphs of the functions $b_{m}-v$ and $v-a_{m}$. In this example, $b_{m}-v>r_{p}(v)-v$ for $v \in\left[0, v_{p}\left(b_{m}, \bar{b}\right)\right]$, where $v_{p}\left(b_{m}, \bar{b}\right)=.25$. It follows that all producers in the interval $[0, .25]$ prefer to trade with the market maker rather than search for a better price in the dealer market. However, for producers in the interval $(.25, \bar{b}]$, we see that $r_{p}(v)-v>b_{m}-v$. Thus these producers choose to search for a better price in the dealer market rather than trade with the market maker at price $b_{m}$. The remaining producers with production costs $v \in(\bar{b}, 1]$ would not gain from trading with the market maker or with any middleman in the dealer market, and so these producers do not participate and earn a net surplus of zero. Symmetrical results hold for consumers.
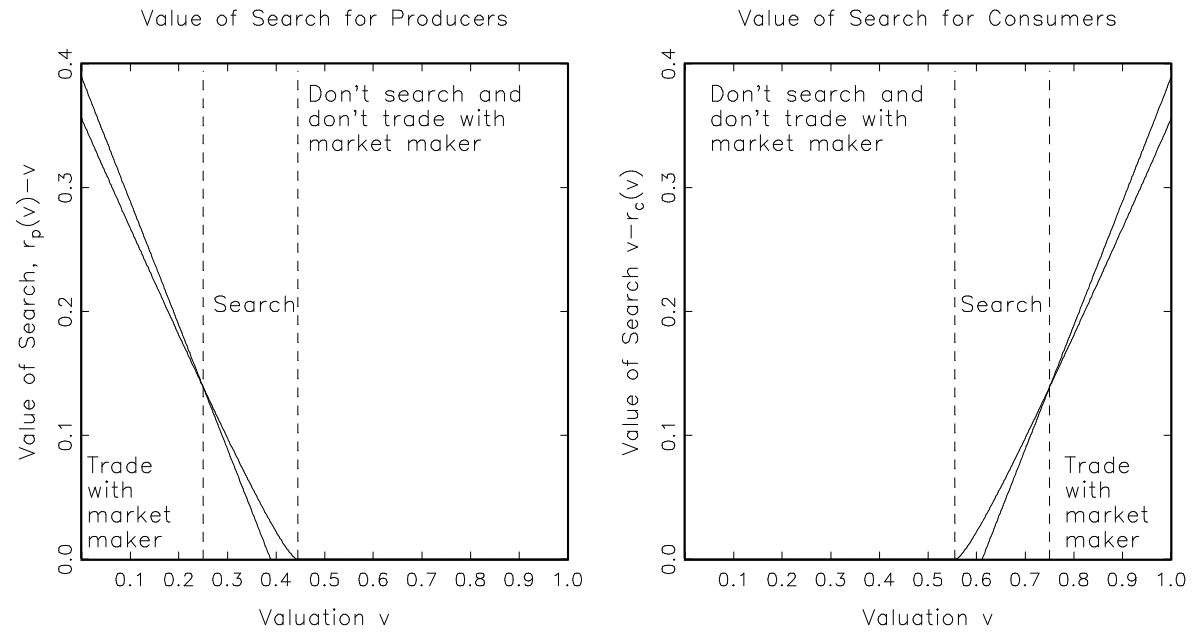

Figure 2: Decision Rules for Producers and Consumers

\subsection{The intermediaries' entry and pricing decisions}

In the previous subsection, consumers and producers took prices as given. In this subsection we analyze the market maker's entry and pricing decision. We then derive the response of the middlemen to the market maker's entry. In particular, there are three possible regimes in equilibrium: an unconstrained monopoly regime, a limit-pricing regime, and a competivitive regime. In first two regimes, the market maker drives all the middlemen out of business. In the competitive regime, a set of middlemen coexists with the market maker. In the limit-pricing and competitive regimes, the existence or potential entry of middlemen in the market limits the market power of the market maker.

All consumers know they have the option of purchasing the commodity from the market maker at price $a_{m}$, and all producers know they can sell the commodity to the market maker at price $b_{m}$. Clearly, 
no middleman in the dealer market would be able to sell at an ask price $a$ higher than $q_{n}$. Similarly, no middleman would be able to purchase the commodity for less than the bid price charged by the market maker. Thus we have:

Theorem 3: $b_{m}$ is the lowest reservation price of producers participating in the dealer market and a lower bound on the support of the distribution of bid prices offered by middlemen. $q_{m}$ is the highest reservation price of consumers participating in the dealer market and an upper bound on the support of the distribution of ask prices charged by middlemen in the dealer market:

$$
\underline{b}=\underline{r}_{p}=b_{m}, \quad \bar{a}=\bar{r}_{c}=a_{m}
$$

Applying the results from section 2, it is not difficult to show that in the presence of a market maker $F_{\alpha}$ and $F_{\beta}$ will still be uniform distributions, but with supports given by $[\underline{a}, \bar{a}]=\left[.75 a_{m}+.25\left(b_{m}+\underline{k}\right), a_{m}\right]$ and $[\underline{b}, \bar{b}]=\left[b_{m}, .75 b_{m}+.25\left(a_{m}-\underline{k}\right)\right]$. Thus middlemen in the dealer market uniformly undercut the posted bid-ask spread set by the market maker. Even though it is common knowledge that a randomly drawn bid from the dealer market will be less than $b_{m}$ with probability 1 , this bid will only materialize after a one-period delay. The highest-valuation buyers and lowest cost producers prefer to trade immediately at the less favorable prices offered by the market maker rather than incur the search/delay costs involved in trying to find a better price in the dealer market.

If the monopolist market maker sets an ask price of $a_{m}$ and offers a bid price $b_{m}$, Theorem 1 implies that the quantity of the commodity that will be demanded by the highest-valuation consumers in the interval $\left.\left(v_{c}\left(\underline{a}, a_{m}\right)\right), 1\right]$ is

$$
Q_{m}^{d}\left(a_{m}, b_{m}\right)=1-a_{m}-\frac{1}{\delta} \int_{\underline{a}}^{a_{m}} F_{\alpha}(a) d a .
$$

Similarly, the quantity supplied by the lowest-cost producers in the interval $\left[0, v_{p}\left(b_{m}, \bar{b}\right)\right)$ is

$$
Q_{m}^{s}\left(a_{m}, b_{m}\right)=b_{m}-\frac{1}{\delta} \int_{b_{m}}^{\bar{b}}\left[1-F_{\beta}(b)\right] d b .
$$

Theorem 4: $Q_{m}^{d}\left(a_{m}, b_{m}\right)=Q_{m}^{s}\left(a_{m}, b_{m}\right) \forall \delta>0$ if and only if $b_{m}=1-a_{m}$.

Proof: If $a_{m}=1-b_{m}$, then corresponding symmetry relations hold in the dealer market: $\underline{a}=1-\bar{b}$ and $F_{\alpha}(v)=1-F_{\beta}(v)$. It is easy to see from formulas (32) and (33) that this implies that $Q_{m}^{l}=Q_{m}^{s}$. Conversely, if $Q_{m}^{d}=Q_{m}^{s}$ for all $\delta>0$, then it must also hold in the limit as $\delta \rightarrow \infty$. But in the limit $Q_{m}^{d}=1-a_{m}$ and $Q_{m}^{s}=b_{m}$.

Clearly the number of intermediaries that can be supported in equilibrium depends on how aggressively the market maker prices. The following result shows that the number of middlemen operating in the dealer 
market is determined by the monopolist market maker's bid-ask spread.

Corollary: If $a_{m}>\max \left[.5\left(1+k_{m}\right), .5(1+\underline{k})\right]$, then the mass of middlemen who are active in the dealer market is given by

$$
N=\max \left(0, a_{m}-b_{m}-\underline{k}\right)=2 a_{m}-1-\underline{k} .
$$

If $\underline{k}=0$, then as long as the bid-ask spread charged by the monopolist market maker is positive, the dealer market will never be driven out of existence by the entry of the market maker. This will be true even if $a_{m}=\underline{a}$, which is the lowest ask price charged by the most efficient middleman (with cost $k=\underline{k}=0$ ) in the search equilibrium without a market maker. The least efficient intermediaries are driven out of the market, and the remaining, more efficient intermediaries are forced to reduce their bid-ask spreads below their preentry values in order to avoid taking a loss. Therefore both the upper and lower supports of the distribution of ask prices in the dealer market fall as a result of the entry of the market maker. Symmetrically, the entry of the market maker increases the lower and upper support points of the distribution of bid prices in the dealer market. This suggests that the entry of the market maker should result in a strict increase in the expected gains from trade for all producers and consumers who participate in the market - regardless of whether they choose to trade with the market maker or search for a middleman in the dealer market.

On one hand, the fact that middlemen uniformly undercut the market maker's posted bid and ask prices could make it unprofitable for the market maker to enter. On the other hand, if the market maker's per unit transactions cost $k_{m}$ is sufficiently lower than $\underline{k}$, the transactions cost of the most efficient middleman, the entry of the market maker might succeed in driving the entire dealer market out of existence. To determine what will actually happen, we need to derive the market maker's profit function and optimal pricing strategy. By Theorem 4 we know that $b_{m}=1-a_{m}$ implies $Q_{m}^{d}=Q_{m}^{s}$, and so we can write the market maker's problem as follows:

$$
\max _{a_{m}, b_{m}}[1+\lambda \rho /(1-\rho)]\left[a_{m}-b_{m}-k_{m}\right] Q_{m}^{s}\left(b_{m}, a_{m}\right),
$$

subject to

$$
b_{m}=1-a_{m}, \quad \frac{1+k_{m}}{2} \leq a_{m} \leq \frac{1+8 \delta+\underline{k}}{2+8 \delta} .
$$

Substituting the constraint $b_{m}=1-a_{m}$, the market maker's problem reduces to maximizing the following quadratic objective function with respect to the single control variable $q_{n}$ :

$$
\Pi_{m}\left(a_{m}\right)=[1+\rho \lambda /(1-\rho)]\left(2 a_{m}-1-k_{m}\right)\left[1-a_{m}-\frac{\max \left[0,2 a_{m}-1-\underline{k}\right]}{8 \delta}\right] .
$$


The market maker's objective is concave in $a_{m}$ and thus has a unique optimal solution provided the market maker's choice of $a_{m}$ does not violate the search equilibrium conditions in the intermediary market. The solution to the market maker's problem and the resulting configuration of the dealer market is given below.

Theorem 5: It is profitable for a market maker to enter the dealer market if and only if the market maker's transaction cost $k_{m}$ satisfies $k_{m}<\bar{k}_{m}$, where

$$
\bar{k}_{m}=\frac{\underline{k}+4 \delta}{1+4 \delta} .
$$

If $k_{m}$ is below the threshold for profitable entry $\bar{k}_{m}$, there are three possible configurations for the postentry equilibrium depending on the model parameters $\left(k, k_{m}, \delta(\rho, \lambda)\right)$. There exist thresholds $0<\underline{k}_{l}<\underline{k}_{m}$ such that if $\underline{k} \in\left[0, \underline{k}_{l}\right)$ the market maker coexists with the most efficient middlemen, but the least efficient middlemen are driven out of business. If $\underline{k} \in\left[\underline{k}_{l}, \underline{k}_{u}\right)$, the market maker's entry drives all middlemen out of business, and the market maker sets "limit prices" that deter the most efficient middleman from entering. If $\underline{k} \in\left[\underline{k}_{u}, 1\right]$ the market maker sets unconstrained monopoly bid and ask prices.

The fundamental condition for the viability of entry by a monopolist market maker given in equation (38) of Theorem 5 has a very simple interpretation. The expression on the right-hand side of equation (38) equals the efficiency level $\underline{k}$ of the marginal middleman in the equilibrium without a market maker. Thus the monopolist market maker's per unit transactions cost must be lower than the marginal cost of the marginal middleman in the pre-entry dealer market equilibrium if entry is to be feasible. However the market maker need not have lower transactions costs than all middlemen in order for entry to be feasible. Even if the market maker's transactions cost is uniformly lower than the transactions costs of all middlemen, the dealer market will not necessarily be driven out of existence.

Corollary 5.0: The thresholds $\underline{k}_{l}$ and $\underline{k}_{u}$ for the limit-pricing and unconstrained monopoly regimes satisfy $0<\underline{k}_{l}<\underline{k}_{u}$ and are given by

$$
\begin{aligned}
\underline{k}_{l} & =\frac{\left(1+k_{m}\right)(4 \delta+1)-1}{8 \delta+1} \\
\underline{k}_{u} & =\frac{1+k_{m}}{2} .
\end{aligned}
$$

We now complete our characterization of the post-entry equilibrium by summarizing the quantities traded by the market maker, his bid-ask spreads, the number of middlemen, and the total quantity traded in the dealer market.

Corollary 5.1: In the unconstrained monopoly regime, the market maker sets bid and ask prices given by

$$
a_{m}=\frac{3+k_{m}}{4}
$$




$$
b_{m}=\frac{1-k_{m}}{4}
$$

The market maker trades the monopoly volume $Q_{m}^{s}\left(a_{m}, b_{m}\right)=b_{m}$. The dealer market is driven out of existence.

Corollary 5.2: In the limit-pricing regime the market maker sets bid and ask prices given by

$$
\begin{aligned}
& a_{m}=\frac{1+\underline{k}}{2} \\
& b_{m}=\frac{1-\underline{k}}{2} .
\end{aligned}
$$

The market maker trades the volume $Q_{m}^{s}\left(a_{m}, b_{m}\right)=b_{m}$. The dealer market is driven out of existence.

Corollary 5.3: In the competitive regime the market maker coexists with the dealer market. The market maker's bid and ask prices are given by

$$
\begin{aligned}
& a_{m}=\frac{3+k_{m}}{4}+\frac{\underline{k}-1}{16 \delta+4} \\
& b_{m}=\frac{1-k_{m}}{4}+\frac{1-\underline{k}}{16 \delta+4} .
\end{aligned}
$$

The quantity traded by the market maker is given by

$$
Q_{m}^{d}\left(a_{m}, 1-a_{m}\right)=Q_{m}^{s}\left(a_{m}, 1-a_{m}\right)=\frac{1-k_{m}}{4}+\frac{1-\underline{k}}{16 \delta+4}-\frac{1}{8 \delta}\left[\frac{1+k_{m}}{2}+\frac{\underline{k}-1}{8 \delta+2}-\underline{k}\right] .
$$

Corollary 5.4: In the competitive regime the post-entry equilibrium mass of middlemen operating in the dealer market is given by

$$
N=\bar{k}-\underline{k}=\left(2 a_{m}-1-\underline{k}\right)=\frac{1+k_{m}}{2}+\frac{\underline{k}-1}{8 \delta+2}-\underline{k} .
$$

Corollary 5.5: In the competitive regime the equilibrium distribution of ask prices quoted by middlemen in the dealer market is uniformly distributed on the interval $[a, \bar{a}]$, where

$$
\underline{a}=\frac{3+k_{m}}{8}+\frac{(8 \delta+1)+\underline{k}(8 \delta+3)}{32 \delta+8}, \quad \bar{a}=\frac{3+k_{m}}{4}+\frac{\underline{k}-1}{16 \delta+4} .
$$

The equilibrium distribution of bid prices is uniformly distributed on the interval $[\underline{b}, \bar{b}]$ where

$$
\underline{b}=\frac{1-k_{m}}{4}+\frac{1-\underline{k}}{(16 \delta+4)}, \quad \bar{b}=\frac{5-k_{m}}{8}-\frac{(8 \delta+1)+\underline{k}(8 \delta+3)}{32 \delta+8} .
$$

Corollary 5.6: In the competitive regime, the equilibrium mass of producers and consumers who participate in the dealer market is given by:

$$
Q_{d}^{d}=Q_{d}^{s}=\bar{b}-\underline{b}+\frac{N}{8 \delta} .
$$



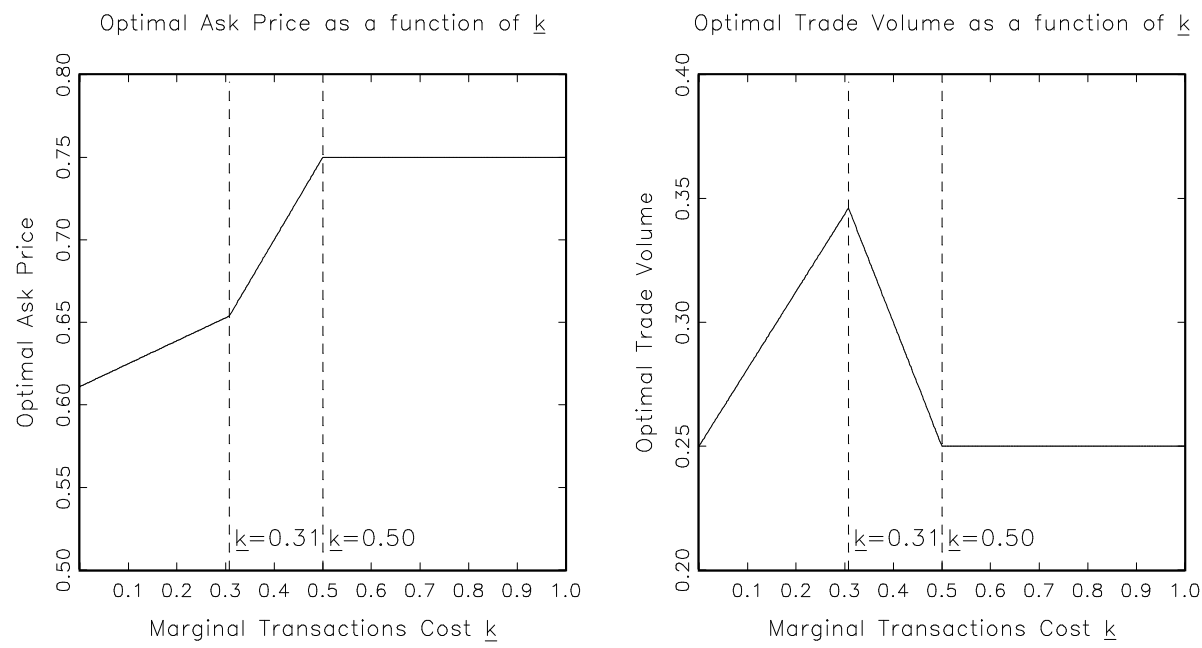

Figure 3: Market Maker's Optimal Trade Volume and Ask Price as a function of $\underline{k}$

Figure 3 illustrates the market maker's pricing and quantity decisions in the three regimes in the case where $k_{m}=0, \rho=.95$, and $\lambda=.12$. These values imply a discount rate of $\delta(\rho, \lambda)=.2$. In this case the cutoff between the competitive and limit-pricing regimes is $\underline{k}_{l}=.31$, and the cutoff between the limitpricing and monopoly regimes is $\underline{k}_{u}=.5$. Note that the market maker's ask price and quantity traded are increasing functions of $\underline{k}$ in the competitive regime. As $\underline{k}$ increases, the dealer market gets increasingly inefficient relative to transacting with the market maker, and the market maker exploits this by raising the ask price (and bid-ask spread). The volume of trade in the dealer market decreases monotonically in $k$ until at $\underline{k}=.31$ the dealer market vanishes. For $\underline{k} \in[.31, .50)$ the market maker adopts a limit-pricing strategy, choosing the largest possible ask price that will not induce entry by middlemen. As $\underline{k}$ increases in this region, the market maker is able to raise prices, leading to a reduction in quantity traded. When $k>.5$, the most efficient middleman is so inefficient relative to the market maker that the market maker no longer fears the possibility of entry and is able to set the bid-ask spread equal to the unconstrained monopoly level of .75 and trade the monopoly quantity of .25 . Thus the market maker's profits increase monotonically for $\underline{k} \in\left[0,\left(1+k_{m}\right) / 2\right]$ but are constant in the unconstrained monopoly regime when $\underline{k}>\left(1+k_{m}\right) / 2$.

\subsection{Equilibria with and without a monopolist market maker}

In this subsection, we compare the equilibrium with a monopolist market maker describe in the previous subsection to dealer-market equilibrium described in section 3. Figure 4 compares the equilibria with and without a monopolist market maker in the case where $k_{m}=\underline{k}=0$, and $\delta=.2$. The market maker trades 
a total quantity of $Q^{m}=.25$, and the dealer maker trades a total quantity of $Q^{d}=.19=.44-.25$, which is less than half the total amount traded in the dealer market prior to the entry of the market maker. The market maker charges a bid-ask spread of $a_{m}-b_{m}=.22=.61-.39$, which equals the bid-ask spread of the most efficient middleman in the equilibrium without a market maker. The average bid-ask spread in the dealer market nearly halves, from .1666 to .085 , following the entry of the market maker. In this case, the market maker's bid and ask prices $b_{m}$ and $a_{m}$ equal the highest bid price $\bar{b}_{d}$ and the lowest ask price $\underline{a}_{d}$, respectively, in the pre-entry dealer market equilibrium. The following corollary characterizes how the market maker's prices relate to the bid-ask prices prevailing in the pre-entry equilibrium in the dealer market.
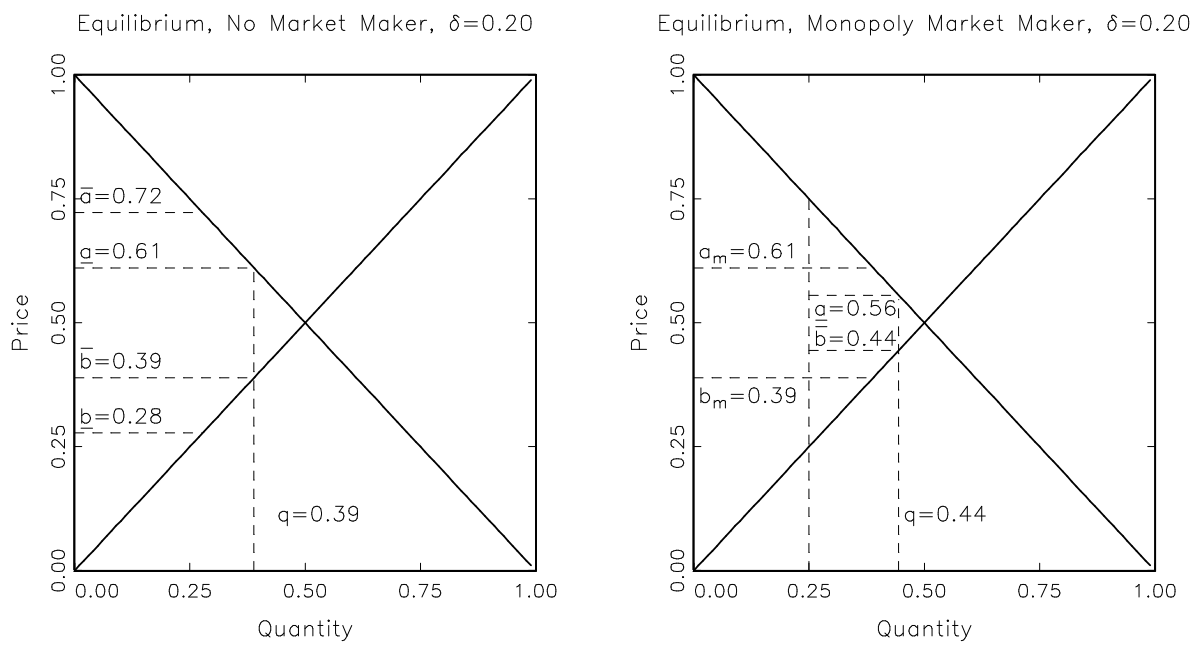

Figure 4: Comparison of Search Equilibria with and Without a Market Maker

Corollary 5.7: Assume that $\underline{k}<\underline{k}_{m}$, so that middlemen coexist with the market maker in the post-entry equilibrium. Let $\left(\underline{b}_{d}, \bar{b}_{d}\right)$ and $\left(\underline{a}_{d}, \bar{a}_{d}\right)$ be the supports of the pre-entry equilibrium distributions of bid and ask prices, respectively. Then we have

$$
a_{m}<\bar{a}_{d}, \quad b_{m}>\underline{b}_{d} .
$$

$a_{m}$ and $b_{m}$ can be smaller or larger than $\underline{a}_{d}$ and $\bar{b}_{d}$, respectively, depending on the values of $\left(k_{m}, \underline{k}, \delta\right)$. However, if $k_{m}=\underline{k}=0$, then

$$
a_{m}=\underline{a}_{d}, \quad b_{m}=\bar{b}_{d}
$$

Proof: Using the formula for $a_{m}$ in equation (42) and the formula for $\bar{a}_{d}$ in formula (21), it is not hard to show that $a_{m}<\bar{a}_{d}$ if and only if $k_{m}<\bar{k}_{m}$, where $\bar{k}_{m}$ is the threshold for which entry by the market maker 
is profitable given in equation (38). If $k_{m}=0=\underline{k}$, then it is easy to see from equations (42) and (21) that $a_{m}=\underline{a}_{d}$. Symmetric arguments establish the results for the case of bids.

Corollary 5.8: Assume that middlemen coexist with the market maker in the post-entry equilibrium. Let $\underline{a}_{m}$ and $\bar{b}_{m}$ denote the lowest ask price and highest bid price set by middlemen in the dealer market in the post-entry equilibrium, respectively. Then

$$
\underline{a}_{m}<\underline{a}_{d}, \quad \bar{b}_{m}>\bar{b}_{d}
$$

If the entry by the market maker eliminates the dealer market in the post-entry equilibrium, then we have

$$
a_{m}<\underline{a}_{d}, \quad b_{m}>\bar{b}_{d}
$$

Proof: Using the fact that $a_{m}=1-b_{m}$ and $\bar{a}_{d}=1-\bar{b}_{d}$ and the fact that $\underline{a}_{m}=.75 a_{m}+.25\left(b_{m}+\underline{k}\right)$ and $\underline{a}_{d}=.75 \bar{a}_{d}+.25\left(\underline{b}_{d}+\underline{k}\right)$, we see that $a_{m}<\bar{a}_{d}$ implies that $\underline{a}_{m}<\underline{a}_{d}$. Now consider the case where the entry of the market maker drives the dealer market out of existence. Consider first the limit-pricing regime. Doing some algebra, we find that $a_{m}<\underline{a}_{d}$ if and only if $\underline{k}<1$. Now consider the unconstrained monopoly regime. The condition $\underline{k}>\left(1+k_{m}\right) / 2$ characterizing the unconstrained monopoly regime implies that $a_{m}<\underline{a}_{d}$. As in Corollary 5.7, a symmetric argument establishes the results for bids.

Corollaries 5.7 and 5.8 formalize the notion that entry of the market maker lowers bid-ask spreads. In the competitive regime the market maker's bid-ask spread is strictly smaller than the worst bid-ask spread charged by the highest-cost middleman in the pre-entry equilibrium. Since the market maker's bid-ask spread is necessarily the worst bid-ask spread in the post-entry equilibrium, it follows that the market maker's entry has succeeded in reducing both the average and the worst bid-ask spreads in the dealer market. Indeed, the entry of the market maker not only narrows bid-ask spreads, but also shifts the entire distribution of ask prices downward. That is, if we let $\underline{a}_{i}$ and $\bar{a}_{i}$ denote the support of the distribution of ask prices in the pre-entry dealer market equilibrium $(i=d)$ and post-entry equilibrium $(i=m)$, respectively, then assuming that the market maker and middlemen coexist in the post-entry equilibrium, we have

Corollary 5.9: If $\underline{k}<\underline{k}_{l}$ and $k_{m}<\bar{k}_{m}$, then

$$
\begin{array}{ll}
\underline{a}_{m}<\underline{a}_{d}, & \bar{a}_{m}<\bar{a}_{d}, \\
\underline{b}_{m}>\underline{b}_{d}, & \bar{b}_{m}>\bar{b}_{d} .
\end{array}
$$

Since the distributions of bid and ask prices have strictly improved in the post-entry equilibrium, it follows that all consumers and producers who participate in the post-entry equilibrium are strictly better 
off as a result of the entry of the market maker. Corollary 5.8 shows that even when the market maker drives the dealer market out of existence, the market maker's ask price $a_{m}$ is strictly less than the valuation $\underline{a}_{d}$ of the marginal consumer in the pre-entry equilibrium. Since the reservation price function for buyers in the pre-entry equilibrium is strictly increasing in $v$ with a minimum value of $\underline{a}_{d}$, it follows that all buyers whose valuations satisfy $v>\underline{a}_{m}$ are strictly better off in the post-entry equilibrium (where $\underline{a}_{m}$ is the lowest ask price in the dealer market in the post-entry equilibrium). We formalize the foregoing discussion as

Theorem 6: Let $\left(r_{c}^{d}, r_{p}^{d}\right)$ denote the reservation price functions for consumers and producers in the dealer market equilibrium before the entry of a market maker. Assume that $k_{m}<\bar{k}_{m}$, so that entry by a market maker is profitable. Let $\left(r_{c}^{m}, r_{p}^{m}\right)$ denote the reservation price functions for consumers and producers in the post-entry equilibrium. Then we have

$$
r_{c}^{d}(v) \geq r_{c}^{m}(v) \quad \text { and } \quad r_{p}^{d}(v) \leq r_{p}^{m}(v)
$$

with strict inequality for producer valuations in the interval $v \in\left[0, \bar{b}_{m}\right)$ and for consumer valuations in the interval $v \in\left(\underline{a}_{m}, 1\right]$.

Proof: If the entry of the market maker drives the dealer market out of existence, we have $f_{c}^{m}(v)=a_{m}$ for $v \in\left[a_{m}, 1\right]$. It is easy to see from the definition of $r_{c}^{d}$ in equation (2) that it is a strictly increasing function of $v$ on the interval $\left(\underline{a}_{d}, 1\right)$ with slope

$$
\frac{d r_{c}^{d}}{d v}(v)=\frac{1}{1+F_{\alpha}^{d}(v) / \delta}>0
$$

where $F_{\alpha}^{d}$ is the distribution of ask prices in the pre-entry dealer market equilibrium. By Corollary 5.8 we have $a_{m}<\underline{a}_{d}$, so that

$$
r_{c}^{d}(v)>\underline{a}_{d}>a_{m}=r_{c}^{m}(v), \quad v \in\left(a_{m}, 1\right] .
$$

Now consider the case where the dealer market coexists with the market maker. In this case $t_{c}^{m}$ will be strictly increasing on the interval $\left(a_{m}, \bar{a}_{m}\right)$ and equal to $a_{m}$ for $v \in\left[a_{m}, 1\right]$, since these latter consumers trade with the market maker by Theorem 5. By Corollary 5.8 we have $\underline{a}_{m}<\underline{a}_{d}$, so that it is sufficient to show that the slope of $r_{c}^{m}$ is strictly less than the slope of $r_{c}^{d}$ on the interval $\left(\underline{a}_{m}, 1\right)$ since $r_{c}^{m}(v)=r_{c}^{d}(v)=v$ for $v \in\left[0, \underline{a}_{m}\right]$. For $v \in\left(a_{m}, 1\right)$ the slope of $r_{c}^{m}$ is zero, whereas from formula (54) we can see that the slope of $r_{c}^{d}$ is strictly positive for $v \in\left(\underline{a}_{d}, 1\right)$. So we have $0=d r_{c}^{m} / d v<d r_{c}^{d} / d v$ for $v \in\left(\max \left[\underline{a}_{d}, a_{m}\right], 1\right)$. For $v \in\left(\underline{a}_{m}, \underline{a}_{d}\right)$ we have $d r_{c}^{d} / d v=1$, whereas $d r_{c}^{m} / d v=1 /\left(1+F_{\alpha}^{m}(v) / \delta\right)<1$, where $F_{\alpha}^{m}$ is the post-entry distribution of ask prices. If $\underline{a}_{d} \geq a_{m}$ we are done. If $\underline{a}_{d}<a_{m}$, we complete the argument by showing that $d r_{c}^{m} / d v<d r_{c}^{d} / d v$ on the remaining interval $v \in\left(\underline{a}_{d}, a_{m}\right)$. If $k_{m}=\underline{k}=0$, Corollary 5.7 implies that 
$a_{m}=\underline{a}_{d}$, and we are done. Corollary 5.9 implies that $F_{\alpha}^{d}$ strictly stochastically dominates $F_{\alpha}^{m}$ on the interval $\left(\underline{a}_{m}, \bar{a}_{d}\right)$; that is,

$$
F_{\alpha}^{d}(v)<F_{\alpha}^{m}(v), \quad v \in\left(\underline{a}_{m}, \bar{a}_{d}\right) .
$$

Since $r_{c}^{d}(v)$ and $r_{c}^{m}(v)$ are both strictly increasing functions on the interval $\left(\underline{a}_{d}, \bar{a}_{m}\right)$ (where $\underline{a}_{d}>\underline{a}_{m}$ by Corollary 5.8), and since the slope of $r_{c}^{m}$ is given by formula (54) but with $F_{\alpha}^{m}$ substituted in place of $F_{\alpha}^{d}$, it follows that the strict stochastic dominance condition implies $d r_{c}^{m} / d v<d r_{c}^{d} / d v$ for $v \in\left(\underline{a}_{m}, \bar{a}_{d}\right)$. But by Corollaries 5.7 and 5.8 we have $\underline{a}_{m}<\underline{a}_{d}$ and $a_{m}<\bar{a}_{d}$, and so the slope of $r_{c}^{m}(v)$ is strictly less than the slope of $r_{c}^{d}(v)$ in the remaining interval $\left(\underline{a}_{d}, a_{m}\right)$. Thus the slope of $r_{c}^{m}$ is strictly less than the slope of $r_{c}^{d}$ over the entire interval $\left(\underline{a}_{m}, 1\right]$, which implies that $r_{c}^{m}(v)<r_{c}^{d}(v)$ for $v \in\left(\underline{a}_{m}, 1\right]$ as claimed.

Figure 5 illustrates the welfare gains resulting from the entry of a market maker. In this example we continue to set $\delta=0.2, k_{m}=0$, and $\underline{k}=0$. Any consumer in the interval $\left(\underline{a}_{m}, 1\right]$ is made strictly better off from the entry of the market maker, where $\underline{a}_{m}=.56$ is the lower support point of the distribution of ask prices in the dealer market in the post-entry equilibrium. The low-valuation consumers located in the interval $\left[0, \underline{a}_{m}\right]$ do not trade, and their welfare is not affected by the entry of the market maker. Clearly, the entry of the market maker causes the lower support of the distribution of ask prices to fall. Thus there is a larger set of active consumers in the equilibrium with a market maker, and the consumers who switch from non-participation to search become strictly better off. Symmetric results apply to producers.
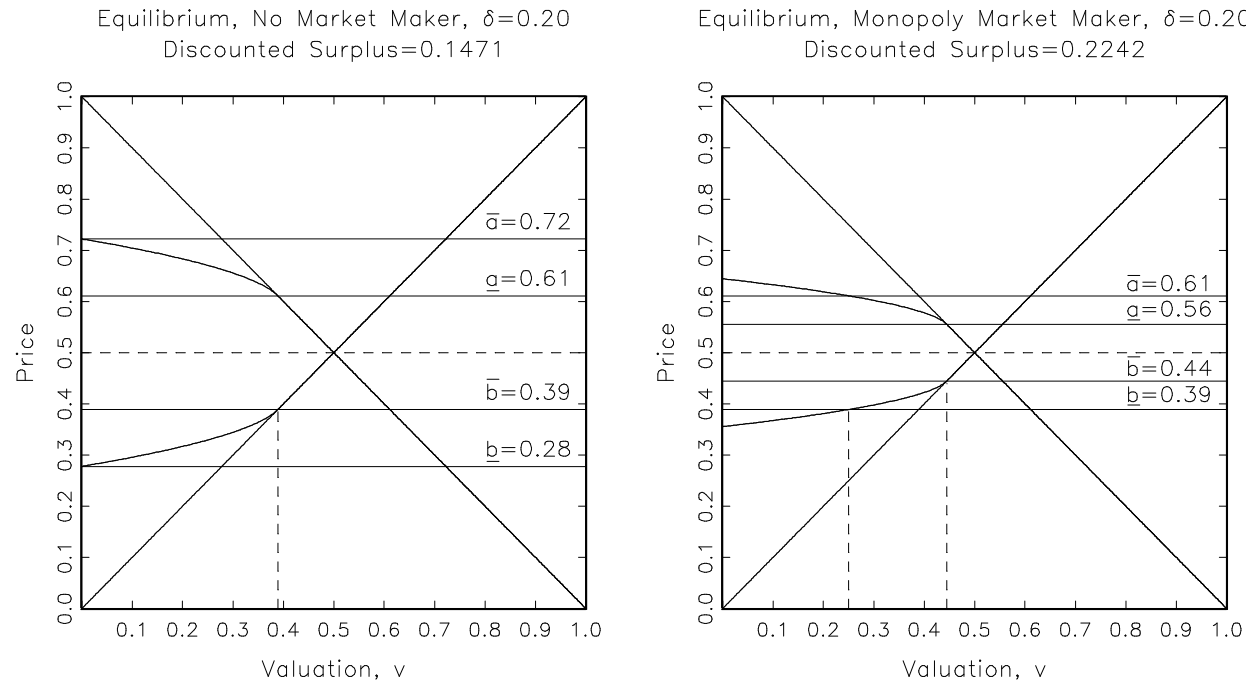

Figure 5: Comparison of Equilibria Before and After the Entry of a Market Maker

Along the abscissa, buyers' valuations are plotted from high to low, whereas sellers' valuations (costs) are plotted from low to high. 
The entry of the market maker halves the volume of trade in the dealer market (from .3889 to .1944) and the discounted profits of middlemen, and cuts profits to one fourth of the pre-entry level (from .0494 to .0123). However the market maker's volume of .25 and profits of .0556 more than make up for the losses incurred in the dealer market, so that overall quantity traded and overall discounted profits increase following the entry of the market maker. Total discounted surplus of consumers (and producers) is .0782 in the post entry equilibrium (i.e., with a market maker) compared with .0489 in the pre-entry equilibrium (i.e., without a market maker). Total discounted surplus (i.e., including the discounted profits of middlemen and the market maker) increases from .1471 in the equilibrium without a market maker to .2242 in the equilibrium after the entry of the market maker. Comparing these total gains from trade with the .25 gains from trade that would be realized in a frictionless Walrasian equilibrium, we see that the entry of the market maker has increased overall market efficiency from 58.8 percent to 89.7 percent.

The rise in total surplus is due largely to the reduction in the deadweight loss of the transactions costs of the less efficient middle men who were forced out of business by the more efficient market maker (whose marginal transactions cost is zero). However, another source of the reduction in deadweight loss is the reduction in search costs due to the entry of the market maker: in the post-entry equilibrium over half of all trades occur at the bid and ask prices set by the market maker, so that a much smaller fraction of trading is subject to search costs in the post entry equilibrium. We obtain these favorable results even though the market maker is a monopolist: ordinarily monopoly power creates deadweight losses rather than reduces them. Provided that the market maker's transactions costs are not too high, publicly posting bid and ask prices represents a superior institution for conducting trade via a search market.

The following theorem shows that entry of the market maker does not always increase total discounted profits: total discounted profits increase in the post-entry equilibrium only when $k_{m}$ is not too high.

Theorem 7: Let $\Pi_{m}\left(k_{m}, \underline{k}\right)$ denote the total discounted profits of the market maker, and $\Pi_{d}^{l}(\underline{k})$ and $\Pi_{d}^{m}\left(k_{m}, \underline{k}\right)$ denote total discounted profits of all middlemen operating in the dealer market in the preand post-entry equilibria, respectively. Let $\underline{k}_{m}$ be given by

$$
\underline{k}_{m}=\frac{36 \delta^{2}+16 \underline{k} \delta^{2}+29 \underline{k} \delta+4 \underline{k}}{52 \delta^{2}+29 \delta+4}
$$

Then $\underline{k}<\bar{k}_{m}$ where $\bar{k}_{m}$ is the threshold for profitable entry by a market maker, given in equation (38). If $k_{m} \in\left[0, \underline{k}_{m}\right)$, the entry of the market maker increases total discounted profits from intermediation, and if $k_{m} \in\left(\underline{k}_{m}, \bar{k}_{m}\right)$, the entry of the market maker decreases total discounted profits from intermediation (relative to the pre-entry equilibrium value). 
Proof: $\underline{k}_{m}$ is the (smallest) solution to the equation

$$
\Pi_{m}\left(k_{m}, \underline{k}\right)+\Pi_{d}^{m}\left(k_{m}, \underline{k}\right)=\Pi_{d}^{d}(\underline{k}) .
$$

Ignoring the common factors $(1+\lambda \rho /(1-\rho))$, which are common to $\Pi_{m}, \Pi_{d}^{m}$, and $\Pi_{d}^{d}$, substituting the formula for $N$ in the pre-entry equilibrium in equation (23) into the formula for $\Pi_{d}^{l}$ in (25) yields

$$
\Pi_{d}^{d}=\left[\frac{1+\delta}{24 \delta}\right]\left[\frac{4 \delta(1-\underline{k})}{(1+4 \delta)}\right]^{2}
$$

Similarly, substituting the formula for $N$ in the post-entry equilibrium from Corollary 5.4, we obtain

$$
\Pi_{d}^{m}=\left[\frac{1+\delta}{24 \delta}\right]\left[\frac{1+k_{m}}{2}-\frac{k(8 \delta+1)+1}{8 \delta+2}\right]^{2} .
$$

Corollary 5.3 implies that in the competitive regime

$$
\Pi_{m}=\left[\frac{1-k_{m}}{2}+\frac{\underline{k}-1}{8 \delta+2}\right]\left[\frac{1-k_{m}}{4}+\frac{1-\underline{k}}{16 \delta+4}-\frac{1+k_{m}}{16 \delta}+\frac{k(8 \delta+1)+1}{8 \delta(8 \delta+2)}\right] .
$$

Substituting these expressions, we see that equation (58) is quadratic in $k_{m}$ and thus has two roots. One root is $\bar{k}_{m}$, since $\Pi_{m}\left(\bar{k}_{m}, \underline{k}\right)=0$ and $\Pi_{d}^{m}\left(\bar{k}_{m}, \underline{k}\right)=\Pi_{d}^{d}(\underline{k})$ by Theorem 5. It is not hard to show that the other root satisfies $0<\underline{k}_{m}<\bar{k}_{m}$. Further using the formulas above, we can show $\Pi_{m}\left(k_{m}, \underline{k}\right)+\Pi_{d}^{m}\left(k_{m}, \underline{k}\right)$ is a strictly convex function of $k_{m}$ on the interval $\left(0, \bar{k}_{m}\right)$. It follows that entry of the market maker increases total discounted profits if $k_{m} \in\left[0, \underline{k}_{m}\right)$, and decreases total profits if $k_{m} \in\left(\underline{k}_{m}, \bar{k}_{m}\right)$.

Figure 6 illustrates Theorem 7 by plotting the profit functions $\Pi_{m}, \Pi_{d}^{m}$, and $\Pi_{d}^{d}$ as functions of $k_{m}$ for $\underline{k}=0$ and $\underline{k}=.6$. Profits of the market maker decline monotonically in $k_{m}$ whereas the profits in the dealer market increase monotonically in $k_{m}$ until $k_{m}>\bar{k}_{m}=.44$. Above this point, entry by the market maker is no longer profitable so $\Pi_{d}^{m}\left(k_{m}, \underline{k}\right)=\Pi_{d}^{d}\left(k_{m}, \underline{k}\right)$ for $k_{m}>\bar{k}_{m}$. When $\underline{k}=0$ we have $\underline{k}_{m}=.12$, so entry of the market maker increases total discounted profits for $k_{m}$ in the interval $[0, .12)$ and decreases total profits for $k_{m}$ in the interval $(.12, .44)$. The right-hand panel of figure 6 plots the profit functions in the case where $\underline{k}=.6$. In this case the larger value of $\underline{k}$ has increased the lower threshold $\underline{k}_{m}$ to .65 and the upper threshold $\bar{k}_{m}$ to .77 . Thus the range of $k_{m}$ for which entry by the market maker increases total discounted profits from intermediation is a monotonically decreasing function of $\underline{k}$, as is evident in the formula for $\underline{k}_{m}$ given in equation (57). 
Pre and Post Entry Frofits, $\underline{k}=0.00$

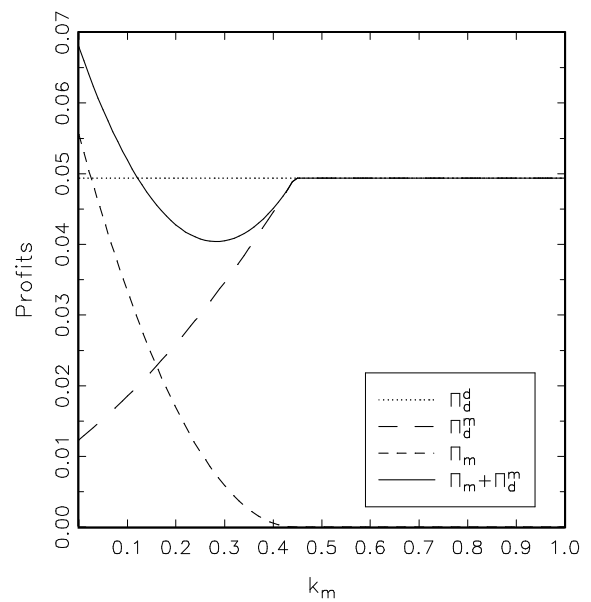

Pre and Post Entry Profits, $\underline{k}=0.60$

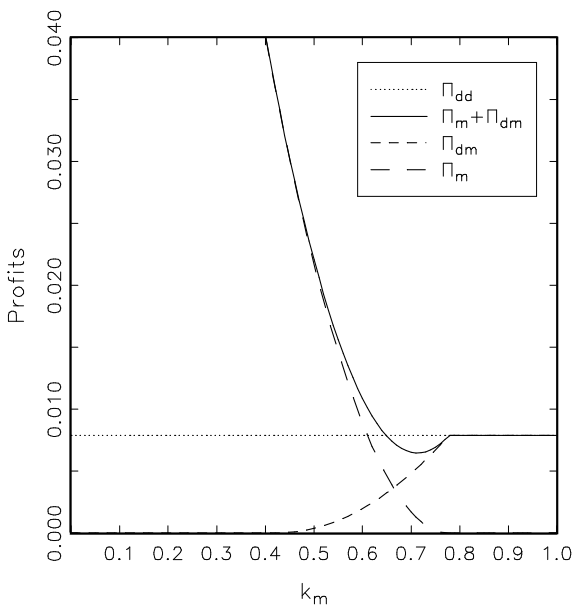

Figure 6: The effect of entry on total discounted profits for various $k_{m}$ when $\underline{k}=0$ and $\underline{k}=.6$

Corollary 7.1: If $\underline{k}_{l}<\underline{k}_{m}$, i.e., if the entry of the market maker drives the dealer market out of existence, the market maker's total discounted profits exceed the total discounted profits of middlemen in the pre-entry dealer market equilibrium.

Since the entry of the market maker strictly increases both consumer and producer surplus, but can decrease total discounted profits from intermediation when $k_{m}>\underline{k}_{m}$, the effect of entry on total discounted gains from trade (i.e., the sum of discounted surplus and discounted profits) is unclear. Figure 7 plots a decomposition of total surplus in the two cases $\underline{k}=0$ and $\underline{k}=.6$. In each case, total gains from trade increase following the entry of the market maker. However, we also see that total surplus is a monotonically declining function of $k_{m}$ until $k_{m}>\bar{k}_{m}$, at which point entry by the market maker is no longer profitable. In figure 7 we indicate the various equilibrium regimes by the symbols $R_{\mathrm{I}}$ (for the unconstrained monopoly regime), $R_{2}$ (for the limit pricing regime), $R_{3}$ (for the competitive regime where the middle man and dealer market coexist), and $R_{4}$ (for the case where $k_{m}>\bar{k}_{m}$ so entry by the market maker is not profitable). Note that surplus is constant as a function of $k_{m}$ in region $R_{2}$ since, in this regime, the market maker's bid and ask prices are functions of $\underline{k}$, not $k_{m}$. 
Welfare Gains from Entry of Market Maker

as a function of $k_{m}$ with $\underline{k}=0.00$

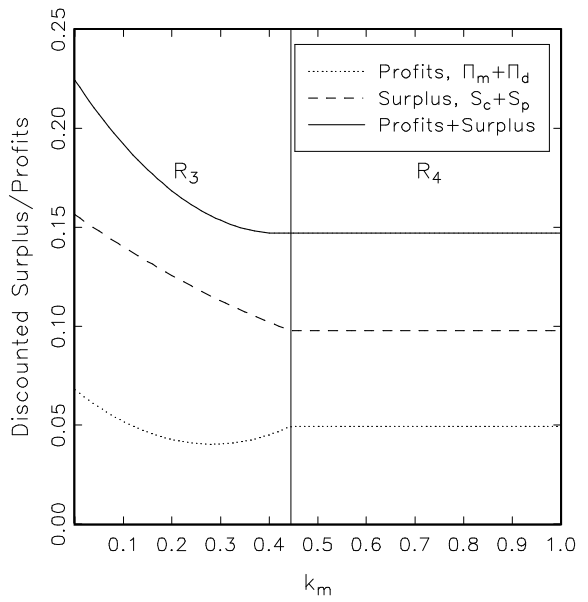

Welfare Gains from Entry of Market Maker

as a function of $k_{m}$ with $\underline{k}=0.60$

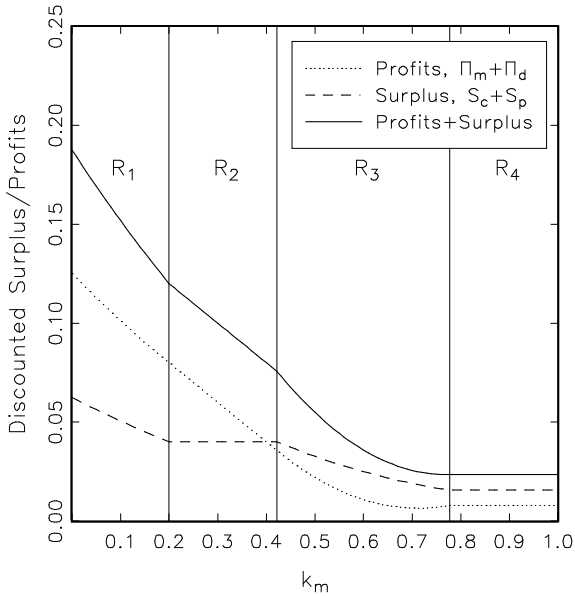

Figure 7: Decomposition of Total Gains from Trade for various $k_{m}$ when $\underline{k}=0$ and $\underline{k}=.6$

The two panels of figure 7 illustrate how the competition between middlemen and the market maker affects the division of the gains from trade between producers, consumers, and intermediaries. Consider the case where the market maker has transactions cost $k_{m}=0$. When the most efficient middleman also has transactions cost $\underline{k}=0$, the dealer market and the market maker coexist and generate total gains from trade of .2242, or nearly 90 percent of the Walrasian surplus of .25. Producers and consumers realize a surplus of .1564 , or nearly 70 percent of the total discounted gains from trade. However when $\underline{k}=.6$, producers and consumers realize a surplus of only .0625 , which is only one-third of the total gains from trade of .1875 . The market maker obtains the lion's share of the surplus, earning the unconstrained monopoly profit of .125 . Thus the market maker is made better off, and producers and consumers are made correspondingly worse off, by any measure that limits entry or increases the transactions costs of middlemen.

Similarly, middlemen can increase their profits at the expense of consumers and producers by promulgating measures that artificially limit entry or increase the transactions cost of the market maker. For example, the left-hand panel of figure 7 indicates that if middlemen were successful in passing a law preventing the entry of market makers, total discounted surplus of producers and consumers would fall significantly. For example in the presence of a market maker with $k_{m}=0$, total producer and consumer surplus is .1564, whereas if entry of a market maker is prohibited, total producer and consumer surplus would fall by 38 percent to .0977 .

Although all of our numerical results indicate that total gains from trade are a monotonically decreasing function of $k_{m}$ for $k_{m}<\bar{k}_{m}$ (which implies that the entry of a market maker always increases total gains 
from trade for any $k_{m}<\underline{k}$ ), we have not yet been able to prove this analytically. Below we simply state our conjecture that entry by the market maker is always welfare-improving.

Conjecture 8: Let $W^{d}$ denote total market surplus in the pre-entry dealer market equilibrium, given in formula (26). Let $W^{m}$ denote total market surplus in the post-entry equilibrium, given by

$$
W^{m}=S_{c}^{m}+S_{p}^{m}+\Pi_{d}^{m}+\Pi_{m}
$$

where $S_{c}^{m}$ and $S_{p}^{m}$ are total discounted consumer and producer surplus in the post-entry equilibrium, respectively. Then $W^{m}$ is a strictly monotonically decreasing function of $k_{m}$ for $k_{m}<\bar{k}_{m}$. In particular, for any $k_{m}<\bar{k}_{m}$ we have

$$
W^{m}>W^{d}
$$

Theorem 9: If $k_{m} \in\left[0, \bar{k}_{m}\right)$, then the mass of middlemen operating in the pre-entry dealer market equilibrium is greater than the mass of middle men operating in the post-entry dealer market equilibrium. When $\underline{k}=0$, the number of middlemen in the post-entry equilibrium is never less than half of the number of middlemen that would be operating in an equilibrium where entry by a market maker is prohibited.

Proof: Let $N^{d}$ be the mass of middlemen in the pre-entry dealer market equilibrium, and $N^{m}$ be the mass of middle men in the post-entry dealer market equilibrium. We have

$$
N^{m}=\frac{1+k_{m}}{2}+\frac{\underline{k}-1}{8 \delta+2}-\underline{k} \leq \frac{4 \delta(1-\underline{k})}{4 \delta+1}=N^{d} .
$$

Theorem 10: If $k_{m} \in\left[0, \bar{k}_{m}\right)$, the total mass of producers and consumers who participate in the market is strictly larger in the post-entry equilibrium than in the pre-entry equilibrium.

Proof: The mass of consumers who participate in the dealer market prior to the market maker's entry is

$$
Q_{d}^{d}=\bar{b}_{d}=\frac{(1-\underline{k})(1+2 \delta)}{8 \delta+2} .
$$

By Theorem 5, when $\underline{k}>\underline{k}_{u}$, the market maker drives the dealer market out of existence, so that $Q_{d}^{n}=0$. Thus the total mass of consumers who participate are those who trade with the market maker, $Q_{n}$. By Corollary 5.1 we have $Q_{m}=\left(1-k_{m}\right) / 4$ in the unconstrained monopoly regime. It is easy to see that $Q_{m}>Q_{d}^{d}$ for $\underline{k} \in\left[\underline{k}_{u}, 1\right]$. In the limit-pricing regime we still have $Q_{d}^{m}=0$, but the monopoly quantity is given by $Q_{m}=(1-\underline{k}) / 2$. Since $Q_{m}>Q_{d}^{d}$ at $\underline{k}=\underline{k}_{u}$, it suffices to show that the slope of $Q_{m}$ is steeper than the slope of $Q_{d}^{d}$ for $\underline{k} \in\left(\underline{k}_{l}, \underline{k}_{u}\right)$. The slope of $Q_{m}$ with respect to $\underline{k}$ is $-1 / 2$ which is less (i.e., steeper) than the slope of $Q_{d}^{d}$ with respect to $\underline{k},-(1+2 \delta) /(2+8 \delta)$. For the final case, $\underline{k} \in\left[0, \underline{k}_{l}\right)$ we proceed 
similarly. We need to show that the slope of $Q_{m}+Q_{d}^{m}$ is steeper than $Q_{d}^{d}$ in $\underline{k}$. The slope of the former is $-(8 \delta+3) /(32 \delta+8)$ and it can be readily verified that this is less (i.e., steeper) than $-(2+2 \delta) /(2+8 \delta)$, the slope of $Q_{d}^{d}$.

\subsection{Limiting properties}

Finally, we summarize the limiting properties of the post-entry equilibrium as $\delta \downarrow 0, k_{m} \downarrow 0$, and $\underline{k} \downarrow 0$.

Theorem 11: In the limit, as $\delta \downarrow 0, \underline{k} \downarrow 0$ and $k_{m} \downarrow 0$ the equilibrium prices, quantities, and producer and consumer surpluses tend to the Walrasian equilibrium values. In the limit the market maker handles half of the transactions in the market, and the most efficient middleman (with $k=\underline{k}=0$ ) handles the rest. Both charge a limiting bid-ask spread of zero at the common Walrasian equilibrium price of $\tilde{p}^{*}=1 / 2$.

This result implies that the coexistence of middlemen and market makers should be fairly robust in a world of steadily declining search and transactions costs due to technological improvements in information and communications technologies. However, the conceptual distinctions between middlemen and market makers start to blur in the limit, since the prices charged by all surviving middlemen are virtually the same as the bid and ask prices charged by the market maker. We view Theorem 11 as a characterization of "efficient markets": when search and transactions costs are small, bid-ask spreads are very narrow, so that there is not much difference between trading with a market maker and trading in the dealer market. For this reason there is approximately a 50-50 split in trade between these two competing institutions. However in the limit it does not matter whether the microstructure of trade involves only middlemen or a combination of middlemen and a market maker. As we saw in section 2, we have convergence to a Walrasian equilibrium even in the absence of entry by a market maker provided that $\delta \downarrow 0$ and $k \downarrow 0$.

The entry of a market maker is much more important when $\underline{k}$ or $\delta$ is large. Conversely, if a market maker is able to obtain unconstrained monopoly power by creating artificial barriers to entry by middlemen or other, competing market makers, then large efficiency and welfare gains can be achieved by breaking down these barriers and subjecting the market maker to competitive pressure to reduce bid-ask spreads. In the next section we will consider the case in which the market maker faces competition from other potential market makers as well as from middlemen.

\section{Search Equilibrium with Competitive Market Making}

Now suppose there is free entry into market making. If there are no fixed entry costs and entry occurs simultaneously, Bertrand-style price competition will ensue among competing market makers. Since all 
producers and consumers can costlessly observe the bid and ask prices quoted by alternative market makers, all trade will occur with the market maker that offers the best bid and ask prices. Bertrand price cutting will result in two possible outcomes, depending on the heterogeneity in transactions costs. If there is more than one market maker who has the smallest per unit transactions cost, price competition will result in a zero-profit equilibrium where the bid-ask spread equals the per unit transactions cost of the most efficient market maker. The division of trade among the competing most efficient market makers is indeterminate. If the most efficient market maker has a strictly lower per unit transactions cost than the next most efficient market maker, the most efficient market maker can earn positive profits by charging a bid-ask spread equal to the per unit transactions cost of the next most efficient market maker.

However we think a model of sequential entry into market making provides a better approximation of reality, as we will see in the examples we discuss in the next section. In addition, the fixed costs associated with entry into market making are likely to be substantial. These fixed costs include advertising costs to make everyone aware of the market maker's identity and where his prices are posted.

In this case, the outcome of a sequential entry process depends on the order in which potential market makers arrive and enter the market. If the first potential entrant can enter profitably, he will do so according to a modified version of theory presented in the previous section. The first market maker will enter if his expected profits from market making exceed the fixed costs of entry. However his expected profits will be lower than the values computed in the previous section since he will anticipate that potential challengers will eventually arrive and force him to limit price, i.e. to reduce his bid-ask spread to the point where the most efficient challenger will not expect to make a profit after the challenger's fixed costs of entry are taken into account. Indeed, a sufficiently efficient challenger could even displace the existing incumbent. In either case the entry decision of the first potential entrant depends on his beliefs about how long he will be able to earn monopoly rents from market making before these rents are partially or fully dissipated by the arrival of more efficient challengers for the position of market maker. A full analysis of this dynamic "entry game" is beyond the scope of this paper. We simply note that the combination of fixed entry costs and post entry competition for the position of market maker will narrow the range of parameter values for which entry by a market maker is profitable. The precise parameter configurations for which entry is profitable will depend on a specification of the fixed costs of entry, and the first potential entrant's beliefs about the arrival of challengers for the position of market making.

It should be clear from the analysis in the previous section that any additional competition between potential market makers, in addition to the competition that already exists between middlemen and market 
makers, will result in further narrowing of bid-ask spreads and additional welfare gains for producers and consumers. Total profits earned by middlemen and market makers will generally fall as a result of additional competition from new potential market makers, but this fall in profits will be more than offset by the increase in expected surplus accruing to consumers and producers.

The stationary equilibrium model used in this paper is not a fully satisfactory framework in which to study the issue of competition between market makers. A model with stochastic arrivals of potential challengers might be one way to incorporate these dynamics, however there difficult issues to consider when there are multiple market makers and consumers are not all instantaneously informed of their existence and bid and ask prices. If producers and consumers need to search in order to discover the bid and ask prices charged by competing market makers, then there is the possibility of "market fragmentation." In this case, competing market makers may not be very different from competing middlemen: producers and consumers will not know which market maker is offering the best bid-ask spread without undertaking a sequential search process to obtain the best price quotes, and most of the benefits of having a single market place where credible bid and ask prices are quoted could be lost.

In addition, if there are elements of increasing returns to scale and network externalities associated with having larger populations of traders (which enable a market maker to have a "thicker" and more “continuous" market), there may be "natural monopoly" elements to market making. In such an environment the equilibrium outcome may be indeterminate, or there may be multiple equilibria. Caillaud and Jullien (2001) analyzed the "chicken and egg" problems arising from the network externalities involved in competition between market makers (or "matchmakers") in a different framework. These issues are worthy of further exploration, but they require a more complicated model than we have employed here. A more realistic model will have to account for various types of non-stationarities and network externalities in order to yield a more satisfactory dynamic analysis of competition in market making in which issues of market fragmentation and natural monopoly can be addressed.

\section{Applications}

The theory in this paper is applicable to a wide range of asset and commodity markets. In this section we look at four markets: the market for commodities in a World War II P.O.W. camp, the U.S. equity market, the U.S. Treasury market, and the U.S. steel market. In the first three markets we observe the co-existence of both middlemen and market makers. In the fourth we observe only middlemen despite recent attempts 
by Enron and two potential web-based market makers, e-STEEL and MetalSite, to enter the market. In light of the quotation at the beginning of the article, we discuss why the brokerage firm Cantor Fitzgerald was able to become a market maker in the U.S. Treasury bond market whereas the two steel dot-coms have not become market makers.

Perhaps one of the best-known examples (at least among economists) of the co-existence of middle men and market makers is the World War II P.O.W. camp described by Radford (1945). In this camp, prisoners traded a variety of commodities among themselves: canned milk, jam, biscuits, and chocolate. In the absence of fiat money, cigarettes became a form of currency. Trade was facilitated by "Exchange and Mart notice boards" on which bid and ask prices for different goods were posted. When a deal was consummated, the posting was crossed out. Radford notes, "The public and semi-permanent record of transactions led to cigarette prices being well known and thus tending to equality throughout the camp." In addition to the Exchange and Mart, middlemen were active in the camp, although they were viewed with disdain:

Despite the fact that his very existence was proof to the contrary, the middleman was held to be redundant in view of the existence of the Shop and the Exchange and Mart. ... And middlemen as a group were blamed for reducing prices. Opinion not withstanding, most people dealt with a middleman, whether consciously or unconsciously, at some time or another. (Radford, 1945, p. 199)

In this camp the Exchange and Mart served the role as a market maker. Both current and historical bid and ask prices were publicly and costlessly observable. As our model predicts, these middlemen did help reduce ask prices. Radford does not mention whether middlemen had any effect on bid prices.

In the contemporary market for U.S. equities there is substantial interest in the question of whether entry of middlemen can reduce the bid-ask spread of market makers such as the New York Stock Exchange (NYSE). The NYSE is a collection of market makers known as specialists. Each specialist is responsible for creating a market in one or more individual securities. Each holds inventories, posts publicly observable bid and ask prices, and reports a history of past transaction prices. ${ }^{6}$ However there is also an active set of middlemen commonly referred to as the "over the counter" market (OTC). Pirrong (2000) estimates that the OTC market accounts for only 8 percent of the volume and 10 percent of the transactions in NYSElisted securities. Despite this small market share, the OTC market does appear to play the role of the

\footnotetext{
${ }^{6}$ Typically a specialist on the NYSE posts prices for only relatively small transactions. Almost all large transactions are negotiated "upstairs" via middlemen; only after the deal is consummated is the transaction price publicly posted.
} 
competitive fringe as in our model. Although the evidence is mixed, several empirical studies, such as Battalio (1997), document that the quoted bid-ask spread for NYSE-listed securities tightens when "third market" dealer/brokers enter and compete against the NYSE to execute trades.

The NYSE also faces increasing competition from other potential market makers such as R. Steven Wunsch's computerized Arizona Stock Exchange (www.azx.com) and the Cincinnati Stock Exchange. In recent years the advent of "electronic communication networks" (ECNs), competition from computerized foreign exchanges, and a change to a more pro-competitive regulatory regime at the Securities and Excahnge Commission (SEC) have subjected the NYSE to much more competitive pressure than it has experienced in the past. ${ }^{7}$ This has forced the NYSE to make changes it had previously resisted such as repealing "Rule 390", moving toward 24-hour trading, and allowing prices to be quoted in decimals rather than in 1/8 increments. ${ }^{8}$ Battalio, Greene, and Jennings (1997) studied the effect of a set of rule changes in the early 1990s that made it easier to trade NYSE-listed securities on regional exchanges. They found that, after the rule changes, bid-ask spreads decreased for about two-thirds of the securities in their sample.

Although the narrowing of bid-ask spreads that Battalio (1997) and Battalio, Greene, and Jennings (1997) find in response to increased competition is consistent with our model, it runs counter to the intuition of a set of models in the financial intermediation literature. See, for example, Easley, Kiefer, and O'Hara (1996) and Fong, Madhavan, and Swan (1999). These papers emphasize the potential adverse selection problem associated with competition between intermediaries. These models generally consider two types of traders: informed and uninformed. If the middlemen are able to selectively trade with only the uniformed traders (e.g. by only accepting small orders), then the market maker is left trading with only the informed traders. This "cream skimming" by the middlemen leaves the market maker at an informational disadvantage against the informed traders. In response, the market maker must widen his bid-ask spread in order not to systematically lose money.

Within this adverse selection literature, Pirrong's (2000) model is perhaps the closest to ours. He considers the effect of competition between a monopolist market maker and a "third market" consisting of middlemen. He focuses on the effects of entry by middlemen on an initial equilibrium with a monopolist market maker, whereas we focus on the effect of the entry of a monopolist market maker on an initial search equilibrium where there is free entry and exit of middlemen. Pirrong's model has differently informed traders, and studies whether the creation of a third market results in free riding on the price discovery

\footnotetext{
${ }^{7}$ See www. island.com for an example of an ECN with posted transactable prices and completely open order books.

${ }^{8}$ NYSE Rule 390, which prevented member firms from trading with middle in the OTC market, was repealed on May 5, 2000.
} 
provided by a monopolist market maker. The NYSE has advanced this latter argument to the SEC as its rationale for the need to limit the formation of third markets and competing exchanges. However, Pirrong concludes that "although free entry to the exchange would maximize welfare, encouragement of a free entry third market may be a second-best response to exchange market power" (p. 2).

Our model is silent on this adverse selection problem, and, as noted above, does not address potential network externalities associated with market making. In our model, free entry by middlemen provides a significant competitive threat to a monopolist market maker, forcing it to substantially reduce its bid-ask spreads. This results in a significant welfare gain to both buyers and sellers. Since middlemen undercut the market maker's quoted prices, their entry increases price dispersion compared with the initial equilibrium. From the monopolist market maker's point of view, this additional price dispersion is unnecessary and evidence that the middlemen are free riding on its price discovery; however, from the point of view of producers and consumers, any additional costs associated with the extra price dispersion are outweighed by the benefits of the reduction in the market maker's bid-ask spreads.

Thirty years ago the secondary market for U.S. Treasury securities was dominated by middlemen. Trades between dealers were made through a small set of inter-dealer brokerage firms. Trades were conducted over the telephone, and dealers did not know the prices other dealers received, nor were customers (e.g., pension funds) shown the prices dealers faced. However, in 1972 Cantor Fitzgerald, a brokerage firm, began allowing dealers to see transactable bid and ask prices on computer screens. Dealers could now see the prices other dealers received. As the quotation at the beginning of the article states, by making its prices transparent, Cantor Fitzgerald "vaulted to nearly monopolistic pre-eminence in the bond market." In 1990, in response to calls from the SEC and customers for greater market transparency, several of the major brokers in the inter-dealer market formed a joint venture, GovPX, to consolidate inter-dealer data. Once consolidated, these data are transmitted in real time to customers through vendors such as Bloomberg. In our view the Treasury market has been transformed from primarily a dealer market like the one described in section 2 to a market with competitive market making like the one described in section 4 .

Today trades in the inter-dealer market are made through brokers either by telephone or over an electronic transaction system (ETS). Like the market maker in our model, ETSs allow dealers to post transactable prices and quantities and execute trades electronically. The Bond Market Association (2001) reports there are currently 33 ETSs active in the U.S. Treasury market, but the two largest ETSs, eSpeed, Inc. and BrokerTec Global, LLC, dominate the market. 9 The Bond Market Association reports that although

\footnotetext{
${ }^{9}$ Cantor Fitzgerald owns 55 percent of eSpeed. BrokerTec is run and owned by a consortium of large Wall Street firms.
} 
the ETSs are capturing a large share of trades in the most liquid issues, trades in less liquid issues still take place primarily over the telephone. We are told by Treasury market participants that the telephone market is helpful in getting information about the depth of the market that is not always available on an ETS. Although our model does not explicitly account for liquidity, one can stretch the model's intuition by interpreting a decrease in liquidity as an increase in the cost of carrying out a transaction. This would suggest that liquid securities are associated with low $k_{m}$ 's relative to $\underline{k}$ whereas the reverse holds true for less liquid securities.

Although precise data on the fraction of inter-dealer trades executed electronically are unavailable, one (albeit noisy) way to measure the movement away from telephone trading and toward ETSs is to view the fraction of total inter-dealer trades not captured by GovPX. Neither eSpeed nor BrokerTec reports its trades to GovPX; therefore the trades recorded by GovPX are dominated by the telephone brokers. All inter-dealer broker trades, including those made through the ETSs are reported to the Federal Reserve Bank of New York. Fleming (2001) reports that GovPX's coverage of the total market has fallen in recent years from 65 percent in 1997 to 57 percent in 1998 and 52 percent in 1999. Although certainly not conclusive, this evidence suggests that the ETSs' market share is increasing.

Although our model predicts that the rise in electronic trading should lead to a decrease in bid-ask spreads in the inter-dealer market, bid-ask spreads are generally higher today than they were in 1997. In particular bid-ask spreads widened substantially in 1998 during the Russian crisis and the near collapse of Long Term Capital Management and have not returned to pre-crisis levels. We do not have access to the high-quality transactions data necessary to tease out the effect of the ETSs on bid-ask spreads, taking into account other broad market events (e.g., the reduction in U.S. Treasury debt during the second half of the Clinton administration and the Treasury's buy-back program).

Just as ETSs have transformed the U.S. Treasury market securities from one dominated by middlemen to one dominated by market makers, it is not hard to imagine similar conversions happening in other markets. In particular, we believe the U.S. steel market is a likely candidate for such a transformation. Spulber's (1996a) model of a dealer market provides a reasonable caricature of the current state of the U.S. steel market. It is a highly competitive and unconcentrated market where over 5,000 "steel service centers" (SSCs) play the role of middlemen between buyers and sellers of steel products. In 1998 three potential market makers - Enron, e-STEEL, and MetalSite - entered the market. None has yet been successful in garnering a significant share of transactions. ${ }^{10}$ From November 2000 to December 2001,

\footnotetext{
${ }^{10}$ Enron declared bankruptcy in December 2001. Although both e-STEEL and MetalSite are still in business, neither firm is
} 
Enron attempted to become a market maker in steel: it posted bid and ask prices on the web for coil steel and held inventory in Chicago to ensure market liquidity. However, as we are writing this paper (in the Winter of 2002), it is our understanding from discussions with executives in the steel industry (but outside of Enron) that the prices currently posted on the web for Enron steel are several months out of date and that Enron is exiting the steel industry. As far as we know, Enron went out of business for reasons unrelated to its maker making position in steel.

In contrast to Enron, neither e-STEEL nor MetalSite claims to be an explicit market maker: neither holds its own inventories, and neither posts its own bid and ask prices. Instead, these sites operate like the Exchange and Mart in the P.O.W. camp discussed above or like the "information gatekeepers" studied by Baye and Morgan (2001). Information gatekeepers are web sites, such as Shopper.com or Mortgage-quotes.com, that centralize dispersed price information and reduce search costs by allowing buyers and sellers to post bid and ask prices on the web.

We can reinterpret the market maker in our model as an information gatekeeper that charges commissions to buyers and sellers rather than buying and selling on its own account and charging its own bid-ask spreads. Suppose the gatekeeper charges a per unit commission or transaction fee $\tau$ to buyers and sellers to post prices on the site. Thus if a buyer posts a bid of $b$ and succeeds in transacting, the total per unit cost he actually pays would be $b+\tau$. Similarly, if a seller posts an ask price of $a$ and transacts, the seller's actual per unit proceeds are $a-\tau$. With a continuum of buyers and sellers, the only Nash equilibrium outcome is for all buyers to post a common bid price $b$ and all sellers to post a common ask price $a$. For any given value of $\tau$, supply and demand for units advertised by the gatekeeper will be equated if and only if $a=1-b$. Consider an equilibrium where $a=b=1 / 2$ and the gatekeeper's commission is one-half the bid-ask spread charged by a monopolist market maker, namely, $2 \tau^{*}=\left(a_{m}-b_{m}\right)=\left(1+k_{m}\right) / 2+(\underline{k}-1) /(8 \delta+2)$, where $k_{m}$ is the gatekeeper's marginal cost per transaction (i.e., the marginal cost of posting a bid-ask pair on the gatekeeper's website). In this equilibrium a seller posts an ask price of $1 / 2$ but net of the commission, receives a per unit sales price equal to $1 / 2-\tau^{*}=b_{m}$, which is the same price the seller would have obtained from a monopolist market maker. Symmetrical remarks apply to buyers. It is immaterial whether a market has a monopolist market maker or a monopolist gatekeeper: both lead to exactly the same equilibrium outcome. ${ }^{11}$ There can be no dispersion in the bid and ask prices posted on the gatekeeper's website, but capturing a significant share of transactions. MetalSite shut down its website and all trading in June 2001, but relaunched it in late November 2001. e-STEEL is now NewView and has switched its focus to licensing inter-enterprise software.

${ }^{11}$ The gatekeeper can use a variety of different commission structures to implement the same outcome as a monopolist market maker. For example, the gatekeeper might charge nothing to buyers who post bids on the site, but a commission equal to 
there will be price dispersion in the dealer market due to the search frictions.

The crucial difference between the two steel dot-coms and the ETSs in the U.S. Treasury market is price transparency. In the Treasury market dealers must post transactable, "take it or leave it" prices. The ETSs in the inter-dealer Treasury market are designed so that no negotiation over price occurs (although negotiation over quantity may still occur). Posted prices are available to all subscribers, and the history of past transactions is made public. In contrast, e-STEEL and MetalSite are designed as "computerized chat rooms" where private transactions are negotiated. Both websites allow buyers and sellers to post prices, but next to each posted price is a "negotiate" or "counter-offer" button. From our discussions with steel middlemen, we learned that these posted prices were much like the list price for a new car; they represent first offers, not take-it-or-leave-it prices. Negotiation is expected. Consequently these two websites are more akin to a computerized extension of the existing dealer or telephone market for steel, but where individual deals are negotiated by typing messages into a computer terminal rather than conducted over the telephone. To the extent that most producers and consumers in the steel market find it easier to negotiate verbally by telephone than by typing messages over a computer terminal, e-STEEL and MetalSite not only fail to perform the role of market maker, but may indeed constitute an inferior technology for intermediation in the dealer market compared with the pre-existing telephone technology.

Furthermore, neither e-STEEL nor MetalSite posts historical transaction data, and both allow buyers and sellers to limit who can view their own postings. There is a question on the "frequently asked questions" page of the e-STEEL web site: "Does e-STEEL create pricing transparency?" The posted answer is "Since e-STEEL is not an auction, your pricing remains private. e-STEEL preserves your current way of doing business since online negotiations and transactions between you and your trading partners are kept private and secure." This emphasis on privacy made it difficult to learn about the current market price of steel from visiting e-STEEL. We conclude that these two web sites are simply offering an alternative communication channel to the telephone to enable buyers and sellers to negotiate privately. Neither fulfills the role of a market maker or an information gatekeeper that posts publicly observable and transactable bid and ask prices. This may be part of the reason that these firms have not been successful in gaining a significant share of transactions in steel.

$\tau^{*}=\left(a_{m}-b_{m}\right)$ to sellers. In this case the equilibrium outcome would be for all buyers to place bids equal to $a_{m}$ and all sellers would place asks equal to $a_{m}$. The price received by sellers net of commission is then the same as the bid price $b_{m}$ that a monopolist market maker would choose. 


\section{Conclusions}

This paper has developed a theory of competitive exchange in which the microstructure of exchange is determined endogenously. We have done this by introducing a fourth type of agent, market makers, into the equilibrium search model with competitive middlemen introduced by Spulber (1996a). Middlemen and market makers represent complementary and competitive exchange institutions: market makers post publicly observable bid and ask prices, whereas prices quoted by middlemen in the dealer market constitute private information that can only be obtained through a costly search process. We have focused on the effect of entry by a monopolist market maker on an initial equilibrium where there is free entry by competitive middlemen.
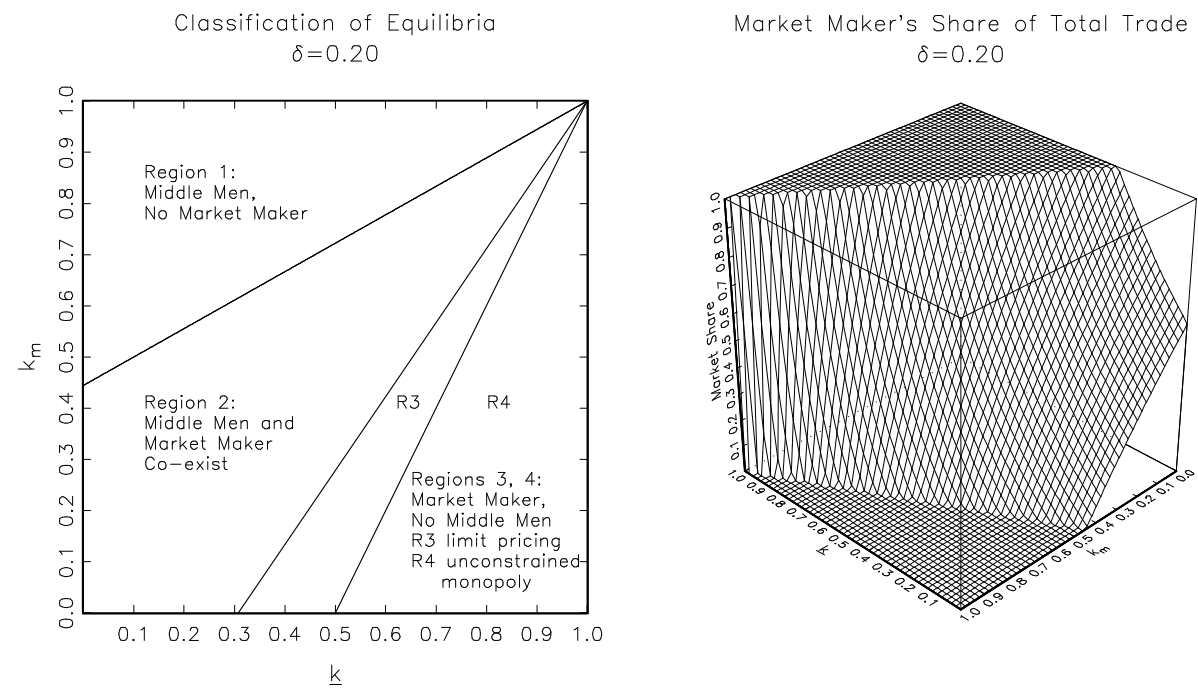

Figure 8: Summary of Equilibria, $\delta=.2$

Figure 8 summarizes the range of equilibrium outcomes predicted by the model. The type of equilibrium outcome depends on three key parameters: the search cost parameter $\delta$, the per unit transactions cost of the market maker $k_{m}$, and the per unit transactions cost of the most efficient middleman $\underline{k}$. The left-hand panel displays the four possible equilibrium regimes that occur for various combinations of the $\left(k_{n}, \underline{k}\right)$ parameters when the search cost is fixed at $\delta=.2$. The model predicts that no market maker will be present if $k_{m}$ is sufficiently high relative to $\underline{k}$ (region 1 ), and that no middlemen will exist if $\underline{k}$ is sufficiently large relative to $k_{m}$ (regions 3 and 4). Region 2 represents the intermediate slice of $\left(k_{m}, \underline{k}\right)$ values that permit the coexistence of middlemen and market makers. The right-hand panel shows the share of trade handled by the market maker. In region 2 this share increases linearly in $\underline{k}$ for any fixed $k_{m}$ or, conversely, declines 
linearly in $k_{m}$ in for any fixed $\underline{k}$. We can conceptualize the steel industry as corresponding to values of $\left(k_{m}, \underline{k}\right)$ in region 1 where entry by a market maker is currently unprofitable. In the securities industry, entry barriers to middlemen and other market makers created by the NYSE correspond to values of $\left(k_{m}, \underline{k}\right)$ that are close to region 3 where the market maker engages in limit pricing; that is, it chooses the largest possible bid-ask spread subject to the constraint that this spread is not sufficiently high to encourage significant entry of dealer/brokers into the OTC market.

We recognize that there are several limitations to our analysis that qualify the types of conclusions we can draw from it. First, as noted in sections 4 and 5, our model does not account for information asymmetries or network externalities, which could affect our conclusions about whether entry by middlemen or competing market makers always benefits buyers and sellers in the market. A richer analysis would be required to determine whether some intermediaries might free ride on the price discovery provided by a market maker, so that market fragmentation could occur and raise traders' search costs and reduce welfare. If there are network externalities in addition to the information problems, there may be conditions under which market making has elements of natural monopoly.

A second limitation is that we assumed that all exchange must be intermediated by either a middleman or a market maker. As we noted in the introduction, only half of the volume of trade in steel occurs through middlemen; the rest does not occur through market makers but through direct transactions between producers and consumers. Hendershott and Zhang (2001) study an extension of Spulber's (1996a) model in which a monopolist producer can sell directly to consumers or through a middleman. Direct sales involve lower search costs than intermediated sales. In equilibrium, the market segments. In a result analogous to ours, high-valuation consumers purchase directly from the producer, and intermediate-valuation consumers choose to search for better prices in the dealer market.

A third limitation of our analysis is that we constrained supply and demand for the commodity for both market makers and middlemen to be equal in every period. As a result, these agents have no inventory holdings in our model. An important function of intermediaries is to hold inventory to provide a buffer stock that offers their customers liquidity at times when there is an imbalance between supply and demand (see Spulber, 1996b). In the securities business, liquidity means being able to buy or sell a reasonable quantity of shares on short notice. In the steel market, liquidity is also associated with a demand for "immediacy" so that a customer can be guaranteed of receiving shipment of an order within a few days of placement. Lacking inventories and stockouts, this model cannot be used to analyze the important role of intermediaries in providing liquidity. 
Although our model is highly simplified and stylized, it provides insights into the organization of a variety of different asset and commodities markets. Consider the two puzzles raised in the introduction. One puzzle was to explain how entry could be profitable even if middlemen uniformly undercut the market maker's publicly posted bid and ask prices. Our explanation is that even though it is common knowledge that middlemen offer better prices, the highest-valuation buyers and lowest-cost sellers still find it optimal to trade immediately at these prices rather than incur the search costs involved in trying to find a better price in the dealer market.

The other puzzle was to explain why market makers intermediate a significant share of trade in financial assets such as bonds and stocks, but virtually none of the trade in steel. Our model suggests that an explanation for this puzzle is that transactions costs for market making are high for commodities such as steel but low for financial assets such as bonds. However this explanation may seem tautological. Why would transactions costs associated with market making be so high for commodities such as steel and so low for financial assets such as bonds?

Recall that $k_{m}$ can be thought of as including a "rebate" to buyers and sellers to offset any transactions costs involved in transacting with the market maker. In financial assets such as bonds and agricultural commodities such as wheat and pork bellies, buyers and sellers (or producers and consumers) may be relatively sophisticated and may be used to conducting transactions through a market maker at a central exchange. Thus, their "hassle" or transactions costs may be fairly low, resulting in a low value of $k_{n}$ relative to $\underline{k}$. However, in the steel market, traders have little experience in conducting transactions over an exchange. They may perceive relatively high transactions costs to doing business with a market maker compared with their local SSC. Thus a new entrant to the steel market may face a different culture than did the initial entrants to the bond or wheat markets, and this difference in culture could translate into a higher effective transactions cost $k_{m}$ as explained in the beginning of section 3.

However, the increasing penetration of computers and the World Wide Web seems to be gradually changing the culture in the steel market, lowering $k_{m}$ and creating the possibility for profitable entry. As we noted, there have recently been several unsuccessful attempts at entry by potential market makers. This may indicate that technology and associated cultural changes are reducing $k_{m}$ relative to $\underline{k}$, moving the market toward the boundary between region 1 (where entry by a market maker is unprofitable) and region 2 (where entry is profitable). From our own observation of the steel market, we think it is only a matter of time before successful entry does occur. Also, some of the problems experienced by the first wave of entrants into the steel market may have been due to the general effects of the dot.com crash of 2001-02, 
and some of these entrants (such as Enron) might have successed in entering the steel market had it not been for problems in their other lines of business.

More generally, our model provides new insights into how the information revolution could affect the microstructure of a variety of different markets. We expect that improvements in computing and communications technologies will tend to drive all three parameters $\delta, \underline{k}$, and $k_{m}$ toward zero. In this case we expect that most markets will ultimately be in a configuration near the origin in region 2 of figure 8. Our theoretical results predict that middlemen and market makers will coexist, with each handling approximately half of the total volume of trade. 


\section{References}

[1] Bakos, Yannis. "The Emerging Landscape for Retail E-Commerce.” Journal of Economic Perspectives 15 (Winter 2001): 69-80.

[2] Battalio, Robert. “Third Market Broker-Dealers: Cost Competitors or Cream Skimmers?” Journal of Finance 52 (March 1997): 341-352.

[3] Battalio, Robert, Greene, Jason, and Jennings, Robert. "Do Competing Specialists and Preferencing Dealers Affect Market Quality?” Review of Financial Studies 10 (Winter 1997): 969-993.

[4] Baye, Michael, and Morgan, John. "Information Gatekeepers on the Internet and the Competitiveness of Homogeneous Product Markets." American Economic Review 91 (June 2001): 454-474.

[5] Bond Market Association. "eCommerce in the Fixed-Income Markets: The 2001 Review of Electronic Transaction Systems” Manuscript. Washington: BMA, December 2001.

[6] Domowitz, Ian. "Automating the Continuous Double Auction in Practice: Automated Trade Execution Systems in Financial Markets." In D. Friedman and J. Rust (eds.) The Double Auction Market: Institutions, Theories, and Evidence (1993): 27-60.

[7] Easley, David, Kiefer, Nicholas, and O’Hara, Maureen. "Cream-Skimming or Profit Sharing? The Curious Role of Purchased Order Flow.” Journal of Finance 51 (July 1996): 811-833.

[8] Fleming, Michael "Measuring Treasury Market Liquidity." Manuscript. New York: Federal Reserve Bank of New York, June 2001.

[9] Fong, Kingsley, Madhavan, Ananth, and Swan, Peter. "Why Do Securities Market Fragment?" Manuscript. Los Angeles, CA: University of Southern California, November 1999.

[10] Garman, Mark. "Market Microstructure.” Journal of Financial Economics 3 (1976): 257-275.

[11] Gehrig, Thomas. "Intermediation in Search Markets." Journal of Economics and Management Strategy 2 (1993): 97-120.

[12] Hendershott, Terrence, and Zhang, Jie. "A Model of Direct and Intermediated Sales." Manuscript, Berkeley: University of California. November 2001.

[13] Caillaud, B. and B. Jullien. "Chicken and Egg: Competing Matchmakers." Manuscript, Toulouse: University of Toulouse. 2001.

[14] Lucking-Reiley, David and Spulber, Daniel F. “Business to Business Electronic Commerce.” Journal of Economic Perspectives 15 (Winter 2001): 55-68.

[15] Neeman, Z. and N. Vulkan. "Markets Versus Negotiations: the Predominance of Centralized Markets" Manuscript, Bost: Boston University. 2001.

[16] O’Hara, M. Market Microstructure Theory. Oxford U.K.: Basil Blackwell, 1995.

[17] Pirrong, Craig. "Third Markets and the Second Best.” Manuscript. St. Louis: Washington University, November 2000. 
[18] Radford, R.A. "The Economic Organisation of a P.O.W. Camp." Economica 12 (November 1945): 189-201.

[19] Rubinstein, A., and A. Wolinsky. "Middlemen." Quarterly Journal of Economics 102 (1987): 581593.

[20] Spulber, Daniel F. “Market Making by Price Setting Firms.” Review of Economic Studies 63 (October 1996a) 559-580.

[21] Spulber, Daniel F. "Market Microstructure and Intermediation." Journal of Economic Perspectives 10 (Summer 1996b) 135-152.

[22] Spulber, D. Market Microstructure: Intermediaries and the Theory of the Firm Cambridge University Press. 1999

[23] Yanelle, M.O. "The Strategic Analysis of Intermediation." European Economic Review 33 (1989): 294-301.

[24] Yavas, Abdullah. "Marketmakers versus Matchmakers." Journal of Financial Intermediation 2 (1992): 33-58. 